\title{
Long-Distance Animal Migrations in the Oceanic Environment: Orientation and Navigation Correlates
}

\author{
Paolo Luschi \\ Department of Biology, University of Pisa, Via A. Volta 6, 56126 Pisa, Italy \\ Correspondence should be addressed to Paolo Luschi; pluschi@biologia.unipi.it
}

Received 11 November 2012; Accepted 21 November 2012

Academic Editors: K. Cheng, S. P. Henzi, and L. Kaczmarek

Copyright (C) 2013 Paolo Luschi. This is an open access article distributed under the Creative Commons Attribution License, which permits unrestricted use, distribution, and reproduction in any medium, provided the original work is properly cited.

\begin{abstract}
A large variety of marine animals migrate in the oceanic environment, sometimes aiming at specific targets such as oceanic islands or offshore productive areas. Thanks to recent technological developments, various techniques are available to track marine migrants, even when they move in remote or inhospitable areas. The paper reviews the main findings obtained by tracking marine animals during migratory travels extending over large distances, with a special attention to the orientation and navigation aspects of these phenomena. Long-distance movements have now been recorded in many marine vertebrates, revealing astonishing performances such as individual fidelity to specific sites and basin-wide movements directed towards these locations. Seabirds cover the longest distances, sometimes undertaking interhemispheric flights, but transoceanic migrations are also the rule in pelagic fish, turtles, pinnipeds, and whales. Some features of these journeys call for the involvement of efficient orientation and navigational abilities, but little evidence is available in this respect. Oceanic migrants most likely rely on biological compasses to maintain a direction in the open sea, and displacement experiments have provided evidence for an ability of seabirds and turtles to rely on position-fixing mechanisms, possibly involving magnetic and/or olfactory cues, although simpler navigational systems are not to be excluded.
\end{abstract}

\section{Introduction}

The concept of animal migration is typically associated to the wide-ranging movements of flying or terrestrial animals, like the epic voyages of Serengeti wildebeests or the migratory flights of the billions of Passerine birds that every autumn move towards low latitude areas to winter $[1,2]$. However, the marine environment also offers amazing examples of longdistance migrations, with a variety of animals that can even cross entire ocean basins to reach profitable foraging grounds or suitable breeding areas. Instances of extended migrations are known in the main groups of marine vertebrates (pelagic fishes, marine turtles, seabirds, pinnipeds, cetaceans) but are not lacking in large invertebrates as well.

Major developments in telemetry systems have recently permitted significant breakthroughs in our knowledge of the oceanic movements of marine animals, allowing researchers to get direct information on the actual routes followed by migrating animals, on the areas visited and, to some extent, on the behavioural patterns displayed (e.g., diving) during their travels. In this way, a number of ecological and behavioural aspects of oceanic migrants have been profitably explored, providing dramatic advances in the scientific knowledge of the studied species. The impressive amount of ecological and behavioural information provided by the American project TOPP (Tagging Of Pacific Pelagics; [3]) provides a clear example of the kind of achievements that can be obtained by systematically applying telemetry techniques to marine organisms. Unfortunately, these developments do not apply universally to all marine migrants, as scant reliable information is available for the smaller and more cryptic species, and notably for most invertebrates (see below). However, for some vertebrate species at least the picture of their migratory behaviour is becoming quite clear, and it is even possible to draw sound inferences on the mechanisms and strategies adopted to accomplish the migratory performances recorded.

A number of papers have recently reviewed the main results achieved by telemetry studies in different groups of marine animals [4-10], emphasizing the relevance of the findings for the general biology of the studied groups. In the present paper, I will provide a comparative overview of the 
tracking data so far available on the long-distance migrations in the marine environment in various animal groups. Given the large number of studies performed, I will not attempt to provide an all-embracing review of all the findings obtained in each group, and will rather focus the orientation and navigation aspects of the published data. To this aim, I will specifically discuss those specific results that are particularly helpful in this respect, including the findings obtained in various experiments specifically planned to investigate the problem. The question of how migrating animals can find their way while covering immense distances, often unerringly reaching their destinations, have long fascinated and puzzled mankind, and only in recent times scientists have started to provide some ground-based answers to these long-standing questions. The problem is even exasperating when movements take place in the open ocean, which appears (at least to us humans) as a most uniform environment, lacking visual cues such as landmarks and beacons that are known to be fundamental in guiding migrations over land. Very little is still known about the orientational performances underlying oceanic migrations, so that any hint that can be obtained from the analysis of migration routes is valuable and potentially most relevant for future studies.

In this paper, I will refer only to animal movements spanning at least a few hundreds of kilometres and that can unequivocally be defined as long-distance ones. This leaves out a number of phenomena that are correctly regarded as migrations, such as the diel vertical migrations within the water column of many planktonic animals, or the shorter migrations of for example, lobsters or crabs [11, 12]. All these phenomena of course have a most important behavioural and ecological value, but they nonetheless are of a different nature than long-distance migrations and so cannot be included in the present paper. Also, while it is evident that any evaluation of the length of a movement should be best made in relation to the size of the actor (for a small organism even a movement spanning over tens of centimetres can be considered a long-distance migration), a distinction based on an absolute spatial scale seems well justified when discussing orientation and navigation aspects of the migratory phenomena. In fact, the environmental cues available to direct short-scale movements are much more abundant and reliable than those accessible to migrants that have to complete journeys of hundreds of $\mathrm{km}$ to reach remote destinations. For instance, keeping and maintaining a given direction in space can be easily done by referring to internal (idiothetic) cues when the movement extend for some tens of $\mathrm{cm}$, while to accomplish such a task while covering hundreds of $\mathrm{km}$ in the ocean, it is necessary to refer to external factors such as the sun's position or the Earth's magnetic field [13]. Similarly, a number of potential factors can be readily identified allowing to pinpoint a specific site when moving from a distance of a few meters (e.g., visual cues, sounds or chemicals diffusing from the target; [14-16]), but no such orienting cues can be immediately determined for a migrant starting a trip of hundreds of kilometres directed towards a remote oceanic target. It is indeed this asymmetry in the availability of orientation cues that makes the "authentic" long-distance migrations so appealing for navigation students-and the orientation abilities of wide ranging migrants so fascinatingly mysterious.

\section{Technical Aspects: An Overview of the Main Wildlife Tracking Systems}

Tracking the long-distance movements of oceanic migrants is no easy task. By definition, these animals are able to cover vast distances and often move in the open sea, that is, in one of the most inhospitable environment for humans. Also, they typically stay submerged for most of (or all) their time, greatly limiting the acquisition or the relay of aerial radio signals, such as those directed to, or coming from, satellites. All this excludes, or makes it very hard, to efficiently rely on many of the methods used to study migrations in terrestrial locations. For example, techniques like radio- or acoustic-tracking (Table 1), which are efficient to study short- and mediumscale movements $[17,18]$, require to maintain a relatively close contact between the animal and the experimenter-a condition that is most difficult to obtain for long periods with marine animals. Satellite telemetry is a viable and very profitable solution for terrestrial or flying animals, but it can be used only for those marine animals that spend at least some seconds at the surface, so is limited to air-breathing vertebrates, although with some exceptions in fishes (see below). Finally, typical migrations (not only in marine animals) do not involve returns to the original site soon after tagging, as migratory cycles are usually completed over periods of one year (or even more, e.g., in sea turtles). As a consequence, reliance on data-logging instruments (Table 1) is problematic and often useless, also given that long-term attachments of instruments are particularly challenging in marine animals. Even the simple recapture of a tagged animal dispersing in the vastness of the ocean is usually unlikely, with the exception of special cases such as commercially valuable species.

Despite these major constraints, a number of techniques are now available to follow marine migrants even during the longest journeys they undertake (Table 1). Some of these methods are relatively straightforward to apply (although often expensive) and so have been, and are being, widely used by a variety of subjects, not always and necessarily with a scientific or academic background. The data obtainable with the various methods are however not of the same quality and reliability, and it is fundamental to be fully aware of the performances of the tracking systems used in each case. A short presentation of the main systems presently used to track marine animals will then be useful for a sound evaluation of the findings obtained, which will be presented in the successive section.

2.1. Acoustic Tracking and Data Loggers. The simplest, and oldest, system to have information on the movements of any animal is to tag it and wait for someone to recapture it sometimes and somewhere. Capture-recapture methods of tagged individuals have historically been the first ones used to study animal migrations and are still used in many cases, having provided relevant information on the general extent of the migrations of many marine animals, including paradigmatic cases such as salmons or sea turtles $[19,20]$. 


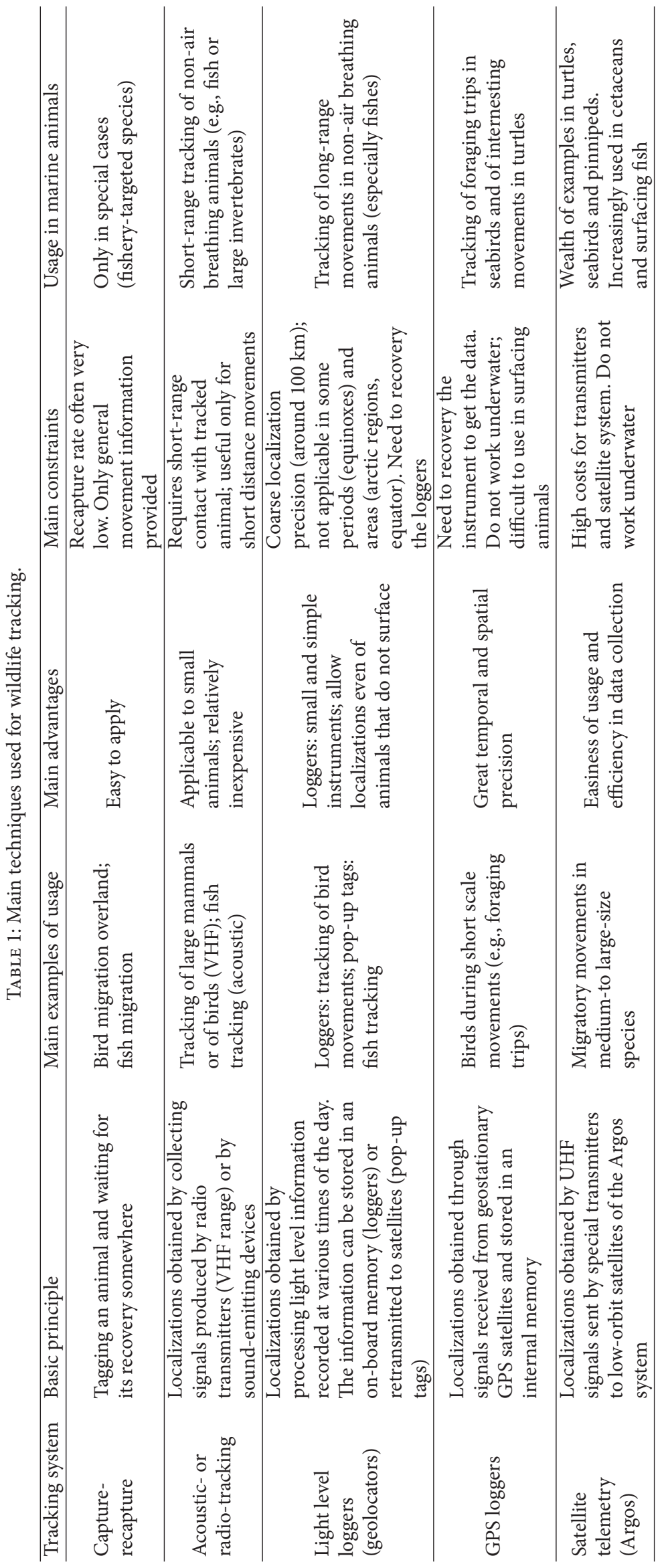




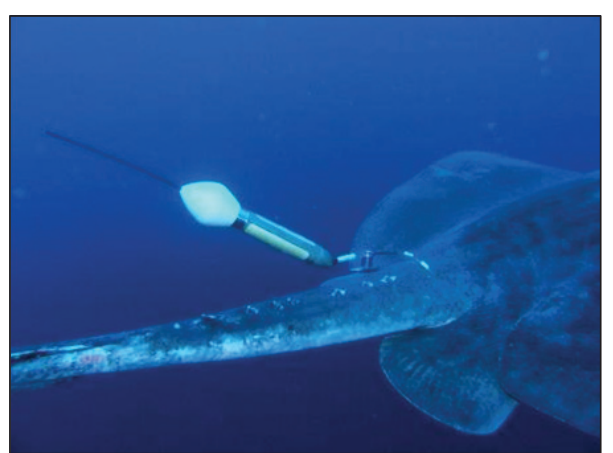

(a)

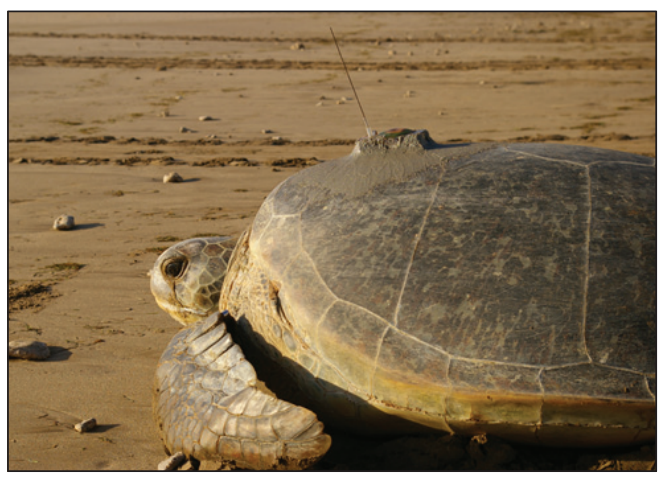

(c)

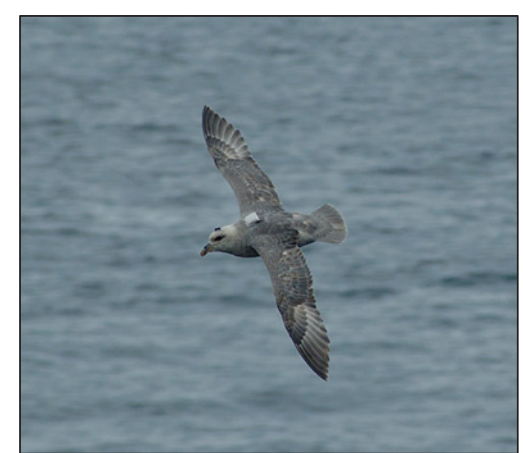

(b)

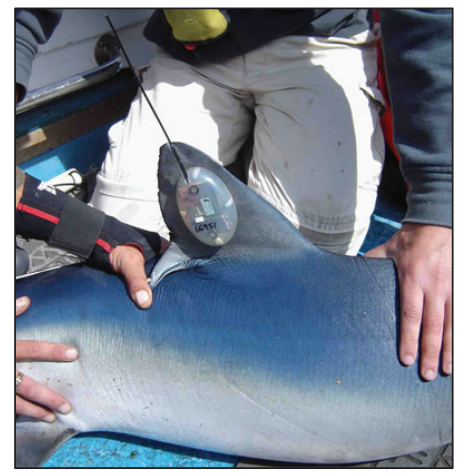

(d)

FIGURE 1: Examples of tracking devices used in marine animals. (a) A pop-up satellite archival tag attached to a short-tailed stingray (Dasyatis brevicaudata) [62]. Photo by Brady Doak, courtesy of Agnes Le Port. (b) A GPS data logger glued to the back of a Northern fulmar (Fulmarus glacialis). Photo courtesy of F. Bonadonna. (c) A green sea turtle (Chelonia mydas) equipped with an Argos-GPS transmitter. Photo by the author. (d) An Argos satellite transmitter attached to the dorsal fin of a blue shark (Prionace glauca). Photo courtesy of D. Sims.

Visual (photographic) identification of specific individuals is also used to investigate the long-distance movements of fish [21] or cetaceans [22, 23]. Since these methods, for their very nature, only give general indications on the kind of movements performed (endpoints of journeys) and give no idea of the actual routes followed by the recaptured animal, they will not be considered further in the present paper.

Acoustic tracking represent a viable solution to reconstruct the movements of marine animals, although over rather small distances (Table $1 ;[18,24]$ ). While radio tracking cannot be reliably used in aquatic environment, acoustic signals propagate very well in water and so can be profitably used to localise animals that do not surface to breathe, like for example, fishes or invertebrates [25-27]. For instance, recent studies employing acoustic tracking have successfully targeted seldom studied species like squids $[28,29]$ or Nautilus [30], revealing significant aspects of their spatial behaviour. The main limit of the technique lies in the fact that acoustic signals have to be collected by local receivers working at relatively small distances (a few kilometres maximum) from the acoustic transmitter. This means that experimenters have to remain at short distance from tracked animals and to follow them if they move, which usually prevents the complete tracking of long-distance migrations and makes acoustic tracking best employed in short-term studies [27, $31]$.
A fairly new system of animal tracking encompasses the deployment of tags recording light levels at different times of the day (Table 1), which then allows, after a complex processing procedures, the determination of latitude and longitude of the animal bearing the instrument [32]. The accuracy of the localization process (now known as geolocation) is generally very low (around $100 \mathrm{~km}$ at best, even when special filters and processing are applied, $[33,34])$, but is still sufficient to reveal at least the general course of wide-ranging movements. Since data loggers recording light level can be very small $(<2 \mathrm{~g})$, this method is frequently used in ornithology, as it is the only way to track the migrations of small passerine birds [35]. Such tiny instruments can remain attached to the animal for long time and so can be recovered even after one year or so, that is, in successive breeding seasons. Geolocation loggers have been successfully used in many fishes and seabirds, leading to most relevant findings (see below). Another fruitful application of geolocation for marine wildlife tracking is to interface light level recorders with satellite transmitters (pop-up tags; Figure 1(a); Table 1), that will be discussed below.

Still about loggers, it is worth to mention a tracking instrument that is becoming widespread in terrestrial studies but is applicable only in a minority of marine cases, the GPS loggers (Figure 1(b); Table 1; [36]). The Global Positioning System (GPS) has rapidly become the most popular satellite navigation system, mostly thanks to its nearly complete 
spatial and temporal coverage and to its high localization accuracy. GPS receivers are now being routinely included in a myriad of electronic appliances (e.g., car navigation appliances, tablets, smartphones, etc.), so GPS is becoming the standard navigation system in everyday life. It is therefore somewhat surprising that wildlife tracking did not benefit from GPS technology until a few years ago, when the first data loggers capable to store GPS locations were fully developed [37-39] and then made available commercially, now even at low price. These loggers can be miniaturised (a few tens of grams usually) while still recording thousands of highaccuracy positions as frequently as $1 \mathrm{fix}$ per second. They are being used in a variety of terrestrial and flying animals [40], with the only limitation being the inescapable need to recover the instrumented animal or at least to approach it to download the data remotely. In the marine environment, besides the usual drawbacks in recovering the instrument, reliance on such a system is made very difficult by the fact that GPS satellite signals cannot be received from underwater, and even airbreathing animals often surface too shortly to permit useful contacts with GPS satellites and generate locations. While technologies allowing rapid acquisition ( $<100$ milliseconds) of GPS data have now been developed so that surfacing animals can be localised [41-43], GPS loggers are mainly used only on seabirds (Figure 1(b)), which can often be recovered easily and reliably at the end of long foraging trips $[44,45]$.

2.2. Satellite Tracking Technologies. Satellite radio-telemetry through the Franco-American Argos System (Table 1) has nearly revolutionised the study of animal migrations and in general of wildlife spatial ecology $[35,46]$. Studies employing this technology to track migratory movements are countless and have been performed on a variety of groups, ranging from large mammals [47] to medium-sized birds [48]. Like other methods employing radio signals, the method works only with aerial transmissions, and indeed Argos satellite tracking and can be used only on those marine animals that surface, at least swiftly, to breathe (Figure $1(\mathrm{c})$ ) or that move close to the sea surface, exposing transmitters purposely attached to their dorsal parts (e.g., fins in sharks; Figure 1(d); [49]).

The system relies on polar-orbiting satellites (six ones functional in 2012) which fly at around $850 \mathrm{~km}$ above the Earth's surface, and which receive signals coming from special radio-transmitters, called Platform Transmitters Terminals (PTTs). The transmissions received are then relayed back to receiving stations on Earth, from which they are then transferred to two global Argos processing centers, one in France and one in the US. The main feature of the Argos system is the ability to localise the PTT anywhere on the Earth's surface upon reception of at least two successive emissions from the same unit during a single overpass of the same satellite, through a complex computational process based on measurements of the Doppler effect of the received signals (see [35] for details). To be useful for localization, the contact between the PTT and the satellites does not need to be continuous (as in the case of GPS) and successive signals can be spaced in time, for example, with a few minutes between them. This greatly increase the system efficiency in animals that surface unevenly, as localizations are possible even when the animal emerges only briefly (less than 1 second in emersion is sufficient for the PTT to transmit), then dives and surfaces again after a few minutes, but still within the same satellite overpass (which lasts about $10 \mathrm{~min}$ on average). The accuracy of the determined location depends on various factors, and especially on the number of PTT signals received within a single satellite overpass. Argos itself accounts for these differences by classifying the locations obtained in 6 location classes, whose accuracy ranges between 150 and over $1000 \mathrm{~m}$. Field tests in marine animals have however challenged the scale of accuracy provided by Argos, highlighting how lower-class fixes are often more accurate than higher class ones ([42, 50], see [43] for a review).

A large part of the popularity of the system lies in its easiness of use: once a PTT is safely attached to the animal under study, the Argos system will do the rest, providing the user with localizations of the tagged animal anywhere it will happen to be and regardless if it frequents inhospitable habitats such as the high-latitude open seas [51] or icecovered areas [52]. Its main shortcomings lie in the costs, of both the transmitters and of the satellite services, which can be substantial, and in the transmitter's size and weight, that is not less than 20-30 $\mathrm{g}$ (but often around over 100-200 $\mathrm{g}$ for marine applications). This limitation mostly derives from the load of batteries, which in turn depends directly on the most common application of the system: satellite transmitters are usually employed to track animals for long periods (months, weeks at very least), and batteries have to be large enough to warrant useful transmissions reaching satellites throughout these periods.

Recently, new instruments have been developed that join together the two satellite navigation systems, that is, Argos and GPS [35, 53, 54]. Basically these GPS-PTTs (Figure $1(\mathrm{c})$ ) consist in a GPS receiver and logger interfaced with an Argos-linked transmitting module: the receiver obtains GPS fixes, logs them in its on-board memory, and the transmitter relay them to the Argos satellites exploiting the possibility of PTTs to encode data obtained by on-board sensors in the transmitted radio signals. The Argos satellites will then only collect these GPS location data and relay them to the ground stations, so being thus used only as a communication channel. The advantages of this technique are manifold: reliance on GPS assures highly accurate locations, obtained independently from the non-continuous coverage of Argos satellites, and GPS localizations are relayed even during single uplinks between the transmitter and the satellite, so that a high-accuracy continuous tracking is usually allowed. The main disadvantages are the higher costs of the units and the heavier weight of the instrumentation. The system is now being used quite extensively [35], even in air-breathing marine animals [55-57] thanks to the above mentioned special technology by which GPS fixes can be obtained even during short $(<0.1 \mathrm{sec})$ surfacings of the animal.

The only technology available to track long-distance movements of non-surfacing animals are the so-called popup satellite transmitters (Figure 1(a); Table 1). These instruments are special satellite tags that are programmed to detach from the animal at a given time, come to the sea surface, and start transmitting to the satellites the information they 
have recorded and stored in a memory during the previous period, when the animal was submerged [58]. The system therefore works in a somewhat similar way as GPS-PTTs, with the Argos satellites being used as a mere communication channel. Argos will determine where transmitter has popped up on the surface, and in some cases this will be the only location obtained for each animal [58-60]. However in most cases the information relayed also consists in light level values by which the animal will be then localised through the geolocation methods described above, thus adding other locations to the final Argos-determined pop-up position. The usefulness of the system is indeed in its permitting the remote collection of light level data, which then allow localization of the animal (albeit with a coarse accuracy) even when it was underwater. Such a performance is so far not consented by any other tracking system, and this explains the popularity of the method among students of fish migrations (see below). Also, other kinds of information can be recorded by the instrument and relayed to the satellites (e.g., depths reached, $[21,60,61])$, thus allowing additional behavioural information to be collected.

\section{Long-Distance Migrations in the Marine Environment}

The various tracking methods discussed in the previous section have provided marine biologists with a considerable assortment of systems to track migrants during their longdistance movements. Thanks to these technical developments quite a wealth of information about animal migrations in the marine realm have indeed been recently collected, although with a clear asymmetry among different groups: the large majority of data have been obtained in (some) vertebrates, while large gaps still exist in our knowledge of the movements of those marine Invertebrates that are thought to move over large distances, such as cephalopods, crustaceans, and possibly jellyfishes. These deficiency is largely due, once again, to the technical difficulties encountered when studying wide-ranging animals that do not surface to breathe, and most information on marine Invertebrates derives from tagging studies [27], so providing only information on the general migratory patterns of the species considered [68, 69]. Acoustic telemetry has provided useful tracking data, but only for movements over short- or medium-scale (tens of $\mathrm{km}$ maximum; $[28,29]$ ). It is possible that in the near future useful information on long-distance movements of large Invertebrates (like squids or possibly jellyfish) will be collected by using pop-up satellite transmitters, that have indeed provided encouraging results so far [70].

3.1. Fish. For quite a long time, the technical challenges highlighted in the previous section have hindered substantial progress in the study of fish migrations, despite it has always been evident that fish do migrate over large distances [71]. Once again, fishery datasets and tag returns data provided useful general information on the amount and extent of migrations, but still missing was the reconstruction of the actual paths followed by migrating fishes, which would provide most important information not only to scientists but also to fishery and wildlife managers. The new tracking techniques outlined above have allowed significant advancements in this field, but even now significant gaps remain, for instance for some of the most iconic (and economically relevant) cases, like eels and salmons [20, 72].

The first tracking data collected through pop-up transmitters only regarded pop-off endpoint positions $[58,59]$, thus providing information basically identical to tag recoveries. Successive studies involved smarter transmitters which also relayed light-level data so that geolocation estimates of positions were possible also during the period between tag deployment and pop off. This development greatly enhanced the system performances and finally permitted to obtain the reconstruction of actual migratory routes of individual fishes [73]. Geolocation estimates of fish movements are now routinely derived from recovery of archival data loggers and pop-up tags, and reconstructions of the migratory courses of a number of different fish species are now available, albeit suffering from the low accuracy inherent in the geolocation process. Additionally, conventional Argos telemetry has been fruitfully applied in some cases by attaching PTTs to the dorsal fins of suitable species (Figure 1(d)), obtaining rather accurate and prolonged routes for the tracked animals. Finally, tracking of long-distance movements without geolocation has been achieved in North Sea plaice (Pleuronectes platessa), thanks to a smart elaboration of diving data (depths) stored in loggers which were translated into horizontal movements by referring to a simulation model of tidal streams [74].

Relevant features highlighted in these studies are the presence of prolonged, often transoceanic, migrations [3, 49, $59,73,75-78]$, sometimes with a clear seasonal periodicity $[3,49,77,79]$, and often accomplished by following straight courses in the open sea $[3,21,49,77]$. In some cases, the reconstructed routes give a somewhat incomplete view of the migrations of the studied fish $[61,80,81]$, providing only a snapshot of a part (although sometimes rather extended in time and/or space) of the travels made during the migratory cycle. In other cases, however, prolonged tracking periods have permitted to outline almost completely the migration circuit of the considered species, revealing important features such as the occurrence of seasonal shuttling migrations between spawning and feeding sites $[21,77,82,83]$ or the long-term fidelity of individual fishes to specific spawning or feeding areas $[21,78,82]$.

One of the best documented case is that of the Atlantic bluefin tuna (Thunnus thynnus), thanks to a series of studies conducted with pop-up transmitters and especially with archival tags, some of which have been recovered after several years $[73,82]$. Tuna tagged in the western Atlantic Ocean migrated both towards the Gulf of Mexico and towards the eastern Atlantic or the Mediterranean Sea, thus undertaking transatlantic migrations. Several individual fishes have shown interannual fidelity to spawning sites in western Mediterranean and, to a lesser extent, to offshore foraging areas in the central North Atlantic, moving seasonally between these two distant regions. In the Northern Pacific Ocean, a similar fidelity was revealed in a number of fish species, 


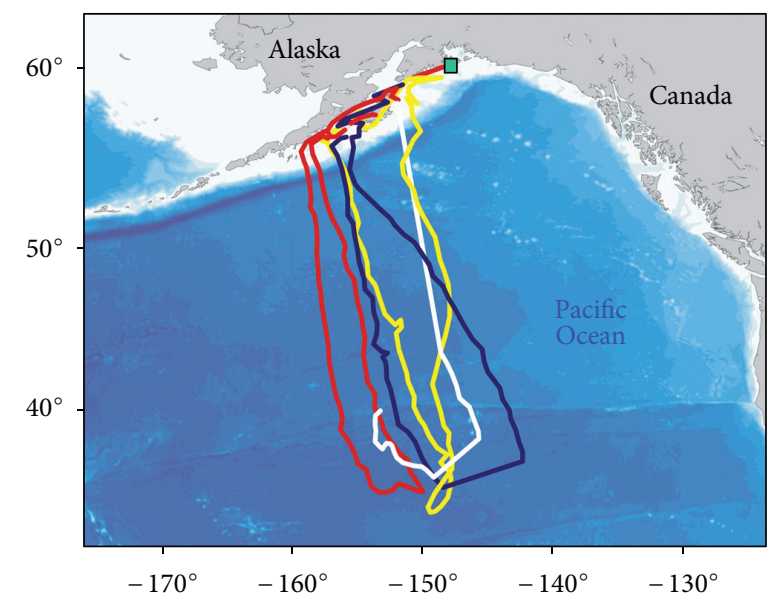

FIGURE 2: Multi-year tracking of the same salmon shark (Lamna ditropis) shuttling between Alaskan coastal waters and a specific offshore foraging area. Each track represents the migratory journey undertaken in a different year. Green square indicate the tagging site. From [3], redrawn.

including white (Carcharodon carcharias; [78]), Mako (Isurus oxyrinchus; [3]), and salmon (Lamna ditropis; [3, 49]) sharks. In many cases seasonal, shuttling migrations connecting specific foraging and reproductive sites have been documented, with fish often moving towards definite, although relatively extended, areas (Figure 2; [3,49]), that are sometimes reached from distant locations over $2,000 \mathrm{~km}$ away [3]. Fidelity to an individually-specific, distant location has also been demonstrated in a female white shark tagged in Western South Africa, which completed a transoceanic migration circuit between Africa and Western Australia extending over 20,000 km [21]. During the migration to Australia, the shark followed a remarkably straight course, which was reconstructed thanks to light-level data relayed by its pop-up transmitter. The shark was seen again at the original site 10 months after tagging but unfortunately the path back to South Africa could not be tracked. Other white sharks have been found to undertake long-distance return migrations from the Cape region towards foraging sites in subtropical waters [21].

3.2. Sea Turtles. The majority of the seven marine turtle species are highly vagile animals, keeping on the move at virtually any stage of their life cycle. Soon after their hatching, newborn turtles of most species embark in oceanic developmental migrations within the major systems of ocean currents, which often extend over large distances and encompass transoceanic legs $[84,85]$. These movements are carried out with the substantial help of the currents, although turtle hatchlings are known to be able to display active, oriented responses helping them to remain within favourable habitats $[86,87]$. Turtles are thought to remain in pelagic habitats for a long time (some years at least, probably up to 10-15 years), mostly continuing to move over large distances in these periods together with ocean current systems. Grownup juveniles are however well able to fully control their displacement within the currents, and indeed have been shown to display erratic movements even against the major currents $[88,89]$.

Juveniles of the most pelagic species (the olive ridley, Lepidochelys olivacea and especially the leatherback turtle, Dermochelys coriacea) are thought to remain in the oceanic environment until reaching sexual maturity and then for the rest of their life, feeding on pelagic planktonic animals such as jellyfish, and usually displaying movements over vast distances [90]. Conversely, the juveniles of the other species leave the oceanic developmental habitats before reaching sexual maturity, moving towards neritic areas while shifting to a benthic feeding and to a more sedentary habit in specific foraging sites $[84,85]$. This ontogenetic model was developed mainly for the two best known species, the loggerhead (Caretta caretta) and the green (Chelonia mydas) turtles and likely applies to the majority of cases of these and of the other species. In loggerheads, however, recent findings have shown that the oceanic-neritic transition is reversible and not obligatory and even the residency in the neritic environment is not always the rule [91-94].

Regardless of where they have spent their developmental phase (i.e., whether in oceanic or neritic areas, or in a combination of the two), the adults of all turtle species breed and nest in specific sites, which usually are the same ones where they have born tens of years before [95]. At each season, adult turtles therefore migrate towards these breeding grounds from far-away foraging areas, which can be specific neritic sites as in green and loggerhead turtles, or wide pelagic areas as in leatherbacks or olive ridleys. Adults then remain in the breeding areas for some time (a few months in females, much less in males), migrating back towards their foraging areas at the end of the season. These usually are individuallyspecific, spatially restricted sites where each turtle reside during the inter-breeding period lasting 2-3 years, and to which they display site fidelity in successive seasons $[96,97]$. The main exception to this rule is once again constituted by the two pelagic species, the leatherback turtle and the olive ridley, which do not head towards a specific site but perform wide-ranging wanderings in oceanic areas [65, 98-101].

Sea turtles have been favourite subjects for satellite telemetry studies from the very initial stages, and indeed quite a wealth of tracking data is now available for most turtle species, especially for adult females (see $[4,6]$ for reviews). From the navigational point of view, the most interesting cases are those where the single turtles migrate between two individually-specific sites which they are faithful to, so that shuttling migrations between the two locations take place. These are especially well known in the herbivorous green turtles, which most commonly (but not exclusively; [102]) forage in neritic locations, often located hundreds or thousands km away from their breeding sites $[63,64,97,102-$ 105]. A paradigmatic example of this kind of migration is that of the green turtles nesting at Ascension Island, which lies just in the middle of the Atlantic Ocean and hosts one of the main green turtle rookeries in the world [106]. Ascension turtles are known migrate between this island and foraging areas located along the Brazilian coast, thus swimming in the open ocean for over $2200 \mathrm{~km}$ [107] — a migratory feat that renders these turtles a peculiar and most relevant example of oceanic 


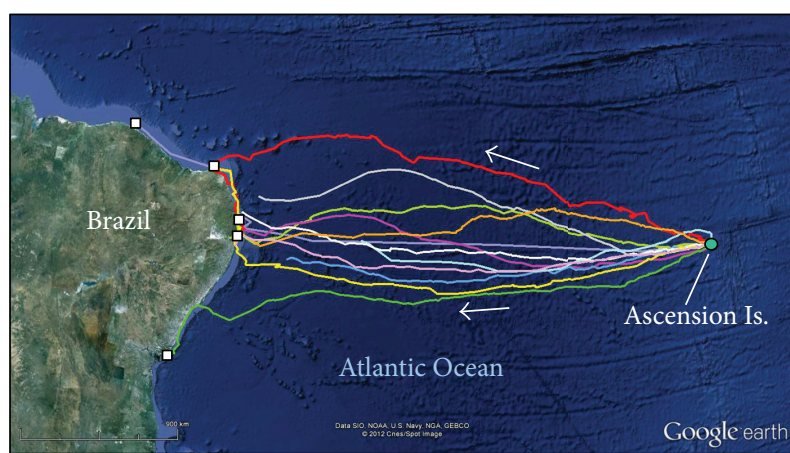

Figure 3: Oceanic migrations of 12 green turtle females nesting at Ascension Is. (green dot) towards their individually-specific foraging grounds along the Brazilian coast (white squares). While most turtles migrated directly to their foraging sites, some of them (e.g., red and yellow track) first reached the coast and then moved along it until getting to their destination. The routes are shown over a Google Earth image. Data from [63, 64].

navigators, as already highlighted by Darwin [108]. Satellite tracking studies of the postnesting migration towards Brazil (Figure 3; $[63,64]$ ) indeed revealed significant navigational feats during the oceanic crossing, such as the presence of long straight segments and the ability to orient towards the individually specific feeding areas from far away [63], although not always following the most direct path (Figure 3). Similar goal-oriented postnesting migrations involving oceanic crossings are known in other green turtle populations (e.g., in Galapagos, Hawaii, or Polynesian islands, [102, 103, 105]), as well as in other species [92, 97, 109-111]. Juveniles too are able to undertake long-distance oceanic migrations and one of the longest journey tracked in a sea turtle actually belongs to a juvenile loggerhead that crossed the entire Pacific ocean covering over $11,000 \mathrm{~km}$ in about 11 months while moving from California towards its Japanese natal area [88].

Leatherback turtles are another species renowned for their long-distance migrations, which in many cases extend over entire ocean basins, as has been clearly documented by satellite tracking findings [65, 98, 99, 101, 112-114]. Being pelagic foragers, leatherbacks range over wide oceanic regions (Figure 4), keeping on the move while hunting jellyfish and other gelatinous species and often following circuitous or undirected routes $[65,99,112]$. In some cases, however, their migratory movements are clearly directed towards specific sites (Figure 4), which are probably individually-known profitable foraging areas, and which can then attract leatherbacks even from far away, sometimes literally from the other side of an ocean $[3,99,113]$. Whichever migratory strategy they adopt and wherever they end up during their wide-ranging wandering movements, leatherbacks however have to come back to their breeding site sooner or later, to which they are known to display site attachment [115]. This specific coastal site has then to be found again after 2-3 years of open-sea journeys, when turtles are largely at the mercy of ocean currents-a performance possible only by relying on remarkable oceanic navigation abilities [116].

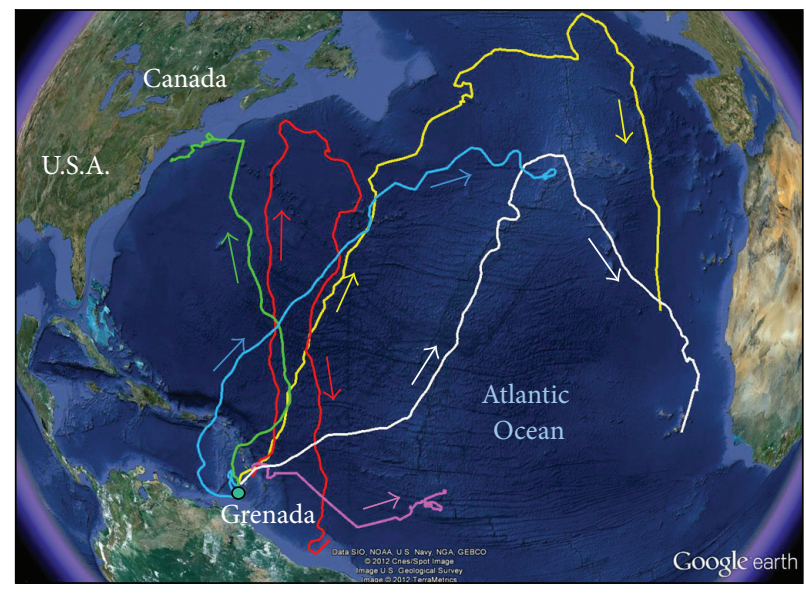

FIgURE 4: Google Earth image showing the migrations of 6 satellite-tracked leatherback turtles (Dermochelys coriacea) nesting at Grenada Is. (green dot), spanning over the entire Northern Atlantic Ocean. Most turtles moved wandered over large oceanic areas, but some (green and red track) migrated directly towards specific sites along the North America continental shelf. Data from [65].

3.3. Seabirds. Birds have always been excellent subjects for tracking studies, and seabirds are no exception. Indeed, the first paper highlighting the performances and the potentialities of the Argos satellite tracking was one on wandering albatrosses (Diomedea exulans) which were tracked during their impressive long-distance foraging trips in the Southern Ocean [117]. Since then, different tracking methods have been largely used to follow the movements of seabirds: GPS loggers have been employed for movements during the breeding season $[44,45]$, while Argos satellite tracking and geolocation archival tags have allowed the monitoring of migratory flights also away from the breeding areas. These studies have involved a variety of species, ranging from penguins $[118,119]$ to albatross and petrels [7], leading to an astounding amount of location data being collected (see e.g., http://www.seabirdtracking.org/). Seabirds attain the longest migrations among all marine animals, and recent tracking experiments have provided spectacular examples of such long-distance travels. Wide-ranging oceanic movements have however been recorded also during foraging trips made in the breeding phase, when birds behave as central place foragers and sometimes move to faraway locations to feed before returning quite directly to the breeding colony, typically following looping paths [117, 118, 120-122].

Albatrosses have been among the first species to be systematically tracked: they cover enormous distances even while foraging, being able to fly up to $15,000 \mathrm{~km}$ in a single trip to forage over wide oceanic areas $[118,120,121,123]$. These foraging trips are most relevant from a navigational point of view because the birds efficiently pinpoint the home island at the end of the excursion [124, 125], sometimes even retracing their zigzag outward journey with an astonishing precision [120] (see [124] for a detailed discussion). Albatrosses range widely also during the nonbreeding phase, which last nearly two years. In disagreement with their name, wandering albatrosses do not wander around the ocean in 


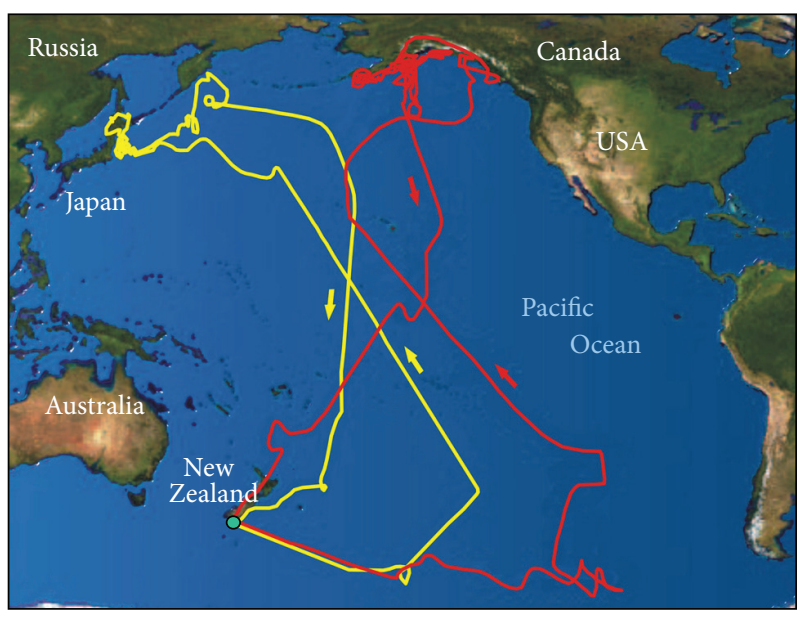

FIGURE 5: Interhemispheric migratory journeys of two sooty shearwaters (Puffinus griseus) moving from their New Zealand breeding colony (green dot) first to oceanic areas in the Southern Pacific Ocean and then to wintering foraging grounds in the North Pacific. Note the figure-of-eight route pattern, which is typical of transequatorial bird migrations. From [66], redrawn.

this period, but rather aim at specific, albeit rather extended, areas distributed from the Subtropical to the Antarctic region [126]. A generally similar migratory pattern has been shown by satellite tracking in short-tailed albatrosses (Phoebastria albatrus; [127]) and in gray-headed albatrosses (Thalassarche chrystostoma), which even showed a remarkable degree of site fidelity to specific regions during their nonbreeding movements [128, 129]. However, gray-headed albatrosses can also undertake global circumnavigations, feeding en route in various sites [128].

Extremely long, interhemispheric migrations have been recently described through geolocation in shearwaters and arctic terns. Sooty shearwaters (Puffinus griseus) nesting in New Zealand and in Falkland Islands have been shown to undertake transequatorial migrations (Figure 5) moving towards wintering foraging grounds in the North Pacific and North Atlantic before returning to their nesting sites in the Southern hemisphere in the following spring $[66,130]$. Reconstructed journeys extended for a total of over 30,000 (Falkland birds) or $60,000 \mathrm{~km}$ (New Zealand birds) and followed a distinctive figure-eight pattern (Figure 5). Broadly similar transequatorial migrations have been recently reconstructed in Manx (Puffinus puffinus) and Cory's (Calonectris diomedea) shearwaters breeding in Northern Atlantic and Mediterranean sea [131-133], in polar skuas (Catharacta maccormicki; [134]) and in arctic terns (Sterna paradisaea), for which the longest migration routes tracked in any animal, spanning over $70,000 \mathrm{~km}$, have been recorded [135]. Tracked terns migrated from their Arctic breeding areas to subantarctic waters, moving along the West African coast or crossing the Atlantic and then hugging the South American continent, before dispersing widely over the Southern ocean and finally returning to the North Atlantic. These transequatorial migrations from both hemispheres share a surprisingly high number of common features, such as the general figure-of-eight course, their occurrence mostly over deep waters, the presence of clearly defined target areas, and sometimes even the sharing of the very same staging areas among different species [130,132, 135]. The sigmoidal paths followed, running counter-clockwise in the Southern part of the oceans and clockwise in the Northern part (Figure 5), indicate that migrations were assisted by global wind patterns [136]. This helped migrating birds to maintain high travel speeds during transiting phases, when they likely feed little rather concentrating their foraging activity in stopover sites distributed along the route [132] or at the wintering areas $[130,133]$. In Cory's shearwaters, repeated tracked of nonbreeding movements of the same individuals revealed that some birds changed drastically their migratory destination in successive seasons, sometimes shifting from an hemisphere to another or from the Atlantic to the Indian Ocean [133].

Finally, it is worth mentioning the most remarkable feats of oceanic navigation that have been shown in a terrestrial bird, the shorebird bar-tailed godwit (Limosa lapponica baueri). Seven godwits were tracked by satellite as they undertook an interhemispheric crossing of the entire Pacific ocean to directly migrate from their breeding grounds in Alaska to wintering sites in New Zealand, 7,000-10,000 km away [137]. Being not adapted to oceanic conditions, these birds most likely flew non-stop for several days (three birds did not pass close to any island for over 7,000 km), moving at high speed $(>60 \mathrm{~km} / \mathrm{h}$ on average), thanks to favourable tailwinds that were specifically selected upon departure from Alaska. These findings highlights how godwits are able to overcome important physiological constraints (e.g., high metabolic rates, dehydration, sleep deprivation) to display extraordinary migratory performances, especially astonishing in view of the fact that the godwits could well be able to avoid the transoceanic path, as they follow the coast of Asia during their northward migration [138].

3.4. Pinnipeds. Together with sea turtles, pinnipeds have been among the first animals to be employed in satellite tracking experiments, primarily thanks to their large size and to their tendency to emerge from water quite often (and sometimes for long periods, during haul-outs). Also, the high probability to recover the same individual after long periods in open sea, rendered these species well suited for the application of data loggers, which provided detailed information on important aspects of their at-sea behaviour, such as diving activity [139]. A large number of studies have investigated the spatial behaviour of different species, with the Southern (Mirounga leonina) and Northern (Mirounga angustirostris) elephant seals representing the best documented cases. Like seabirds, many species display long-range movements already during the breeding period, shuttling between their colonies and offshore foraging areas, often located hundreds of km away [140-143]. For instance, breeding Antarctic (Arctocephalus gazella) and Northern (Callorhinus ursinus) fur seals were found to forage in colony-specific open-sea areas $[140,144]$, with individuals displaying fidelity in the choice of the foraging destination and in the routes followed $[140,143-145]$. To return to the breeding site, the seals can 


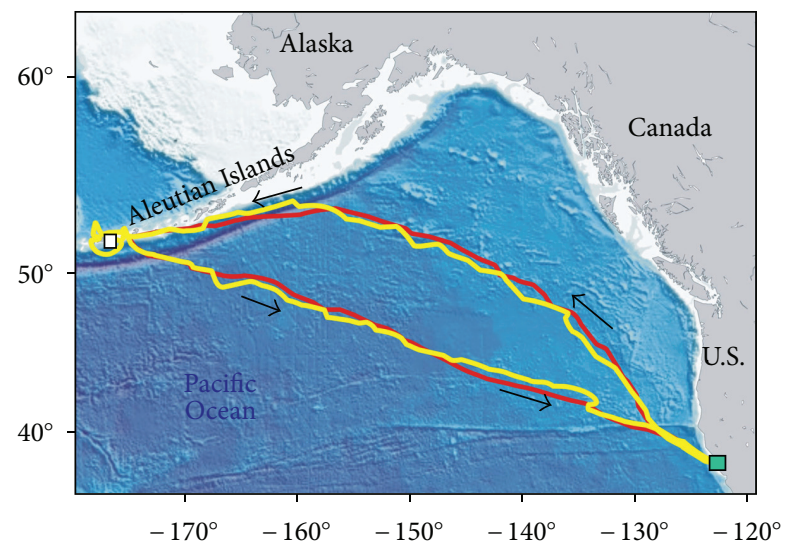

FIGURE 6: Successive migrations of the same male Northern elephant seal (Mirounga angustirostris) tracked during its fall (yellow line) and subsequent spring (red line) journey from its Californian rookery (green square) to the same foraging area (white square) in Western Aleutian Islands. From [67], redrawn.

either follow a looping route or retrace their outward paths $[140,141,143,144,146]$.

During postbreeding and postmolt migrations, most species range over wide oceanic areas, with seals foraging over continental shelf or pelagic areas, often far from the rookery $[3,51,67,123,147-150]$. In elephant seals, adults migrate to faraway foraging areas after the end of the breeding season, but they remain anyway linked to the breeding site for moulting, where they return after 2-4 months. After a few weeks spent ashore to moult, they migrate away again, coming then back to the breeding site at the following breeding season, 4-8 months later. All this actually results in a double, longrange migration accomplished each year [147, 151], with each individual often returning to the very same foraging area during postbreeding and postmolt migrations $[3,67]$. During both migrations, Southern elephant seals breeding in subantarctic islands undertake circumpolar journeys towards disparate foraging sites in the Southern Ocean extending from subtropical to Antarctic waters [51, 147], which are sometimes shared with newly weaned pups [149]. Migrations usually encompass an initial, rapid transit phase towards the offshore foraging destination (often quite similar in different individuals of the same colony), that is followed by slower, meandering, and circumscribed movements due to feeding and then by a rapid and directional leg leading them back to the rookery [51].

Northern Elephant seals breeding in California represent the best studied case. Satellite tracking revealed a sexual segregation of migration destinations: males migrate to sites along the continental shelf up to the Aleutian Islands which are reached with steady and rather direct routes (Figure 6), while females range over extended deep-water areas in the Northeastern Pacific (Figure 7), displaying more wandering movements and likely feeding en route [67]. The analysis of individual routes highlights impressive features: during the return trip towards the California rookery the

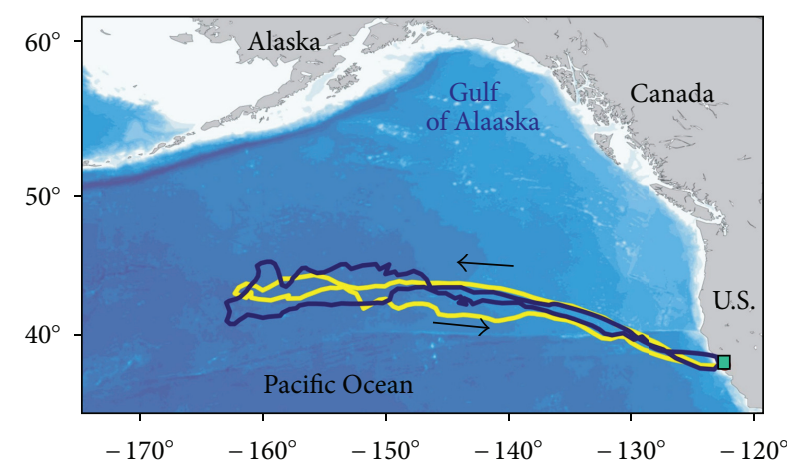

Figure 7: Post-moult (fall) migrations of the same female Northern elephant seal, tracked in 2004 (blue line) and 2005 (yellow line) as it shuttled between its Californian rookery (green square) and open-sea foraging areas in North-eastern Pacific Ocean. From [3], redrawn.

seals can either follow a course immediately leading them home with astonishing precision (Figure 6) or they can even "retrace" the outward journey with remarkable accuracy (Figure 7; $[3,67]$ ). Also, males that have been tracked in successive trips showed an extraordinary consistency in their movements: the routes followed during the fall migrations were sometimes nearly identical to those made in the successive spring (Figure 6), just like they were following a preexisting path or a specific topographic configuration like a coastline [67]. All these performances are truly astonishing for animals moving in the open ocean, where of course no such paths or landmarks exist.

3.5. Cetaceans. A series of technical and logistical problems have long prevented long-term tracking of the migrations of the many cetaceans which, thanks to resightings of marked or photo-identified individuals, were known to move over long distances $[22,23,152]$. The main problems regarded the drag produced by instruments fixed to the external side of the fusiform cetacean body and, especially, how to safely attach the instruments, given that most cetaceans (most notably whales) cannot be captured and the instrumentation has then to be deployed remotely [5, 31]. To circumvent this latter problem, a number of ingenious solutions (brilliantly reviewed in [5]) have been attempted in whales to attach the instruments (usually PTTs) in a safe and long-lasting manner while approaching the animal. The currently used systems involve arrow-shaped implantable PTT models which are inserted into the whale's skin by means of poles, crossbows, or air-powered applicators. In this way, nearly the entire tag lies beneath the skin, providing a firm attachment for the instrument while also greatly reducing its drag. The PTTs are usually expelled from the body after some time, but still long enough to track the animal for a significant amount of time (some months at least, with peaks of over 1 year; [153]). In smaller cetaceans, similar penetrating techniques are adopted but with greater caution given the thinner skin layers. Suction cups are often preferred, but they provide 
a weaker attachment and instruments attached in this way usually have a much shorter retention time [31].

Most migration studies have been done on baleen whales, and especially on large species, and only in a few cases longdistance movements have been tracked in toothed whales $[154,155]$. Like in fish, many tracked routes are somewhat incomplete, showing only parts (albeit sometimes quite extended) of the migratory journeys, so that an inclusive view of the migratory behaviour is often prevented. The available tracks have however revealed some most interesting features of the whale migratory behaviour, like the ability to maintain straight paths in the open sea [156-158] and the amazing directedness of the path towards a remote target $[5,153,155]$. Complete year-round migrations have been reconstructed in a minority of cases $[153,155]$, documenting the annual migratory cycle between low-latitude breeding grounds and the foraging areas in high-latitude, more productive waters. A large number of blue whales (Balaenoptera musculus) have been tracked for several months as they moved between their southern breeding grounds (in California, USA and in the Gulf of California, Mexico) and foraging locations along the Northern Pacific coast and the gulf of Alaska [153]. The routes were mostly in a corridor along the American continental shelf and specific statistical models revealed an alternation of straight transiting legs, and of slower spatially-restricted movements, likely for feeding and/or breeding purposes. In killer whales (Orcinus orca), rapid, highly directed migrations between Antarctic and subtropical waters have been documented, with a whale being able to return with amazing precision to the tagging location in Antarctica after a trip of nearly $9400 \mathrm{~km}$ [155]. Similar straight movements extending over hundreds of $\mathrm{km}$ have been documented in humpback whales (Megaptera novaeangliae) breeding in Hawaiian waters, that migrated towards specific summer foraging locations in Alaska or Russia following very rectilinear routes, quite evidently directed towards their specific targets [5].

\section{Orientation and Navigation during Long-Distance Movements}

The findings presented in the previous section raise a number of questions regarding the orientation and navigation abilities underlying the sometimes amazing migratory performances recorded. How can an animal unerringly move towards remote, specific destinations following straight, direct routes in the apparent uniformity of the high seas? How can a bird or a turtle return faithfully to its home island after months or even years of transoceanic or interhemispheric movements? Or a seal return with a remarkable precision to its breeding site after weeks spent foraging in the middle of the ocean, sometimes closely retracing its outward journey? Unfortunately, sound answers to such questions are not available, as the scientific research on these aspects have only recently started to provide ground-based conclusions only on a few specific cases (reviews: [125, 159-161]).

The majority of the experimental work on the problem has been performed on sea turtles, where laboratory and field experiments have specifically been planned to investigate the navigational abilities of these long-distance migrants $[160,161]$. For instance, displacement experiments have been performed on turtle females nesting on oceanic islands to investigate their homing abilities [104, 162-164], as well as to test the role of specific navigational cues such as wind-borne $[165]$ or magnetic $[55,166]$ information. Relevant experiments of this kind have also been performed on seabirds [167, 168]. The body of evidence obtained from these studies is not yet large nor unequivocal, also given the logistical difficulties encountered while experimenting on a subject like open-sea orientation, especially in natural conditions, but at least some indications have been provided on the possible mechanisms and cues likely involved in sea turtle and seabird oceanic navigation $[125,159,161]$. In the following, the experimental findings obtained in turtles and birds will be used as a starting point to discuss navigation issues in the other cases of longdistance migrations in marine animals previously described.

4.1. Biological Compasses. To explain the process of returning towards a previously known site (homing behaviour), navigation students usually distinguish two distinct, successive stages: an initial determination of the direction to keep (and perhaps the distance to travel) to get back home, and the subsequent assumption and maintenance of that homing direction. The first phase is usually called "map step" ("knowing where" process; [169]), the second "compass step" ("getting there" process; [169]). This conceptual scheme was first proposed by Kramer [170] to account for bird navigation and originally involved reliance on a "true" map sense (by which birds can refer to local cues to determine the direction towards their home area; [171]). In the recent literature, however, the "map step" is commonly used in a broader sense to include any process allowing animals to establish their position with respect to a given destination, that is, to navigate $[169,171])$. This task can be accomplished by using navigational mechanisms other than true maps, like those relying on cues collected en route (route based orientation) or others [171]. It is convenient to adopt this broader map-andcompass framework to discuss the navigational performances of marine animals (see also [171]).

To accomplish the compass step, animals are known to refer to a number of orienting stimuli in the environment $[13,169])$. Locally available cues such as landmarks are often used to keep and maintain a direction wherever possible, but animals are also known to be able to use one or more biological compasses, by which a direction is assumed with respect to universally available stimuli, such as the sun's position (sun compass) or those deriving from the Earth's magnetic field (magnetic compass). Reliance on biological compasses of various kind is quite well ascertained in many different animal species [13], including some marine animals, mostly thanks to laboratory experiments in which the orientation of the animal is tested in arenas of various kind under controlled conditions. For instance, specific tests in water tanks have shown that newborn and juvenile sea turtles possess a magnetic and a sun compass [172-176]. Similar results have been obtained for a magnetic orientation in salmons $[177,178]$. 
Indications on the possible usage of a biological compass are much more difficult to be obtained in natural conditions. The remarkable straightness of the open-sea courses recorded in many tracked animals have sometimes been considered suggestive of a reliance on a compass of some kind [21, $25,104,149,158,179,180]$ and its persistence during the night [181], even when moonless [104, 180], indicated a possible reliance on a magnetic compass. However, the simple presence of straight segments during high-sea travels is not a full guarantee that the tracked animal has really maintained a constant heading during these legs [26]. The reconstructed routes derive from a combination of the animal's active swimming and of current drift, and currents often contribute substantially to the observed ground-related movements of marine animals [182, 183]. Therefore, the straightness of tracked routes can largely derive from the current action, with the animal not necessarily orienting in the same direction. However, in hammerhead (Sphyrna lewini) and blue (Prionace glauca) sharks, highly directional movements were recorded in the absence of relevant currents, pointing to an ability of these animals to rely on a compass while swimming at depth [25, 179]. More recently, studies employing special data loggers recording animal headings have provided convincing evidence of a compass orientation in the open sea. Both loggerhead turtles and northern elephant seals have been clearly shown to be able to keep and maintain a given direction while swimming at depth in the open ocean, and to continue to do so even at night, suggesting reliance on a magnetic compass [184-186]. Thus, the evidence derived from these field studies, together with the various laboratory findings described above, makes it reasonable to assume that one or more biological compasses should be within the orientation tools available for the oceanic travels of marine animals. It is likely that a sun compass is used by those animals travelling at or close to the sea surface, and a magnetic compass is employed in nocturnal and/or deep-water orientation (but see [187] for contrasting evidence in a salmon).

4.2. Navigational Mechanisms. Much more uncertain (and interesting) is the problem of the map step, that is, to understand in which way animals establish their position with respect to a given site during long trips away from it. A number of navigational mechanisms permitting such performances have been described in different animals [171], but not all of them can be reliably used by for movements taking place in the ocean. For instance, the open sea seems essentially featureless (at least to an human eye), being devoid of signposts, landmarks, and any visual reference. Any navigational mechanism based on reliance on visual cues (including pilotage or development of familiar area maps) seems therefore unlikely. However, it cannot be excluded that animals moving in the open sea may still refer to some kind of signposts ("seamarks"; [125]), perhaps of magnetic $[188,189]$ or olfactory [125] nature, which would provide them useful navigational information. In seabirds, it has been hypothesised that olfactory cues may even constitute an odorous landscape $[125,190]$ allowing birds to develop a sort of familiar area map in the oceanic environment by which to recognize previously visited open-sea locations and navigate over large oceanic areas. The best candidate odorous substance involved in these processes is dimethyl sulphide, which is produced by phytoplankton and thus constitutes an indicator of high productivity oceanic areas [191], but seems also likely to be engaged in the formation of putative "seamarks" and olfactory landscapes. High sensitivity to dimethyl sulphide has been demonstrated in seabirds [15, 191], and similar indications have been found in harbour seals (Phoca vitulina; [192]), African penguins (Spheniscus demersus; [193]), and loggerhead sea turtles [194].

Carr [195] proposed the somewhat extreme possibility that oceanic migrants may have no specific navigational information and so move at random (or at least employing only a strategy of systematic search) to find their target more or less by chance. The directedness and efficiency of many journeys directed towards a destination that have now been tracked make this idea extremely unlikely, although the behaviour of experimentally displaced turtles has revealed unsuspected abilities to perform wide-ranging looping movements [163-165]. These are considered searching attempts for home [161], a sort of last resource for turtles that are disoriented and cannot navigate back to their home island which correspond to the similar behaviour shown, at much smaller spatial scales, by displaced desert ants [196]. Indeed this searching behaviour is not inefficient, since in most some cases displaced turtles did find the home island again, after days or weeks or such long, convoluted journeys [163-165]. It cannot be excluded that similar searching abilities can be profitably used (not only by turtles) during the natural migrations as well, for instance to overcome the effects of navigational imprecision or deflections during the migratory journey (see below).

Better suited to explain long-distance navigation are those mechanisms by which the animal is informed in some way about the distance and direction to travel to reach its target. Some birds for instance possess an innate knowledge of the length and the direction(s) of their migratory flight and use this information at least during the first migratory journey [197]. Similar vectorial information is provided by routebased navigation mechanisms [171], and in particular by path integration [198], in which the animal records the distance and the direction of its own outward movement and uses these egocentric cues to continuously calculate and update a vector leading to its goal. Can an Ascension-bound turtle be able to find the island by simply moving to the easternmost coast of Brazil and then steering due East for a certain amount of time, thus relying only on such a simple knowledge of the migratory course, that may be innate or even acquired in some way? Or can an elephant seal or a wandering albatross be able to memorise the directions and the distance travelled to reach its oceanic foraging site(s), so that it can return to the breeding island by integrating or reversing the outward path? In theory all this is not impossible, but an oceanmoving animal relying only on such vectorial information would be faced with a number of problems. The main drawback of relying on navigational mechanisms providing only vectorial information (including the otherwise efficient 
path integration) lies in their sensitiveness to two factors: (i) possible inaccuracies in determining the directions held or the distances covered (both in the outward collection of input data and in the expression of the vector-based movements) and (ii) unwanted displacements whose passive translations cannot be incorporated in the animal's egocentric recordings. Both these factors cannot be compensated or corrected if the animal's movements are not anchored in some way to nonegocentric stable cues in the environment (e.g., landmarks). As such, they are therefore expected to play a major role during movements taking place in the ocean, where passive displacements frequently occur because of the drifting action of winds and currents. So an Ascension turtle heading due East from Brazil may not get close to its target because of current drift or steering inaccuracies occurring during the $2200 \mathrm{~km}$ crossing, and will then have no way to correct or compensate for this mistake. For this specific case, it has been estimated that a systematic error of even 2 degrees in steering East will lead to missing the island of about $77 \mathrm{~km}$ [161], a distance at which that turtles have been shown to be unable to orient directly towards Ascension [163, 165]. Current drift is likely to produce even larger deflections from the steered course, and to determine similar problems and mistakes, also in the case of animals relying on egocentric information obtained during their previous movements. A foraging seal or albatross homing to their breeding island by path integrating (or by retracing) their outward journey without taking currents or winds into account, will probably have little chance to get safely home (but see $[125,199]$ for other considerations on the matter).

A simple way to deal with the drift problem would be to detect current or wind drift while moving, thus immediately compensating for the induced translations from the due course. However, such an apparently straightforward feat is thought to be nearly impossible for movements done in the absence of stationary references, like during flights in clouds or during open sea travels, including those of human seafarers $[13,125,183,200]$. Thus, once again migrating in the ocean poses formidable challenges to marine animals, which are indeed thought not to be able to detect drift and so to compensate its effect on their migratory journeys [116, 161]. These considerations highlight the critical importance to take currents (and winds) into account when interpreting the spatial and orientation behaviour of marine animals on the basis of tracked routes [182, 201]. For instance, several recent studies in turtles, birds and pinnipeds have integrated tracking data with oceanographic information, so as to study the relationship between the recorded movements and the oceanographic conditions of the areas crossed. Such an approach has been very fruitful not only to highlight important aspects of the animals' spatial ecology like their association with oceanographic features [142, 150, 202-204], but also to assess the role of ocean currents in determining the actual routes followed during open sea movements [149, $150,203,204]$. Quantitative approaches based on estimations of currents are particularly informative in this respect [112, $164,166,182,205]$. Tracking data only allow to reconstruct the animals' ground-related paths as derived from telemetric estimations of locations, which may differ, even substantially, from the water-related route that the animal is actually following, just because of current or wind drift [182]. Unfortunately, disentangling these two components is not a straightforward task given that it is difficult to reliably determine the currents actually encountered by migrants during their travels. Only recently, specific oceanographic procedures have been developed to reliably estimate current direction and speed over most oceanic regions [182, 201, 206]. In marine turtles, the application of these techniques to the oceanic movements of some species have revealed a number of previously unknown aspects of their spatial behaviour, showing that the effects of current drift on turtle oceanic movements are not negligible and that the groundrelated tracks obtained are not always informative of the actual, water-related behaviour and orientation of the turtles $[164,166,182]$. None of these studies have however provided any indication that turtles are able to detect the drift while swimming in the open sea (see also [207]).

Reliance on vectorial information may still play a role in oceanic movements aiming at relatively large targets (e.g., fairly wide foraging areas, like those of Pacific predators; [3, 77]) or at coastal sites, when any error can be corrected with the help of topographic features. For instance, the postnesting migrations of Ascension green turtles are not always directed precisely towards the individually-specific foraging site along the Brazilian coast, and the turtles first reach the coast at a site even quite far away from their foraging area and then move along coastline until reaching their final destination (Figure 3), likely correcting the navigational imprecision during the oceanic leg of their migration [64]. Even in journeys directed to isolated targets, local cues detected in the relative proximity of the goal can be involved in the final stages of target localization [125, 161]. For instance, satellite tracking experiments with nesting turtles displaced away from Ascension Island have revealed that turtles were able to home much more easily when released downwind from their target than upwind [165]. In this case, it is hypothesised that the stable Southeast trade winds flowing in the area may create an asymmetry in the oceanic area around the island helping the turtles in their island-finding behaviour. For instance, winds may generate a sort of plume extending for some tens of $\mathrm{km}$ towards Northwest direction which may act as an aerial beacon, possibly thanks to the turtles' ability to perceive airborne odours [208]. In this way, turtles which end up inside such plume would then be attracted by the island from some distance, with the plume functionally expanding the size of the island in Northwest direction [163]. Such a beaconing action in the Ascension case was also proposed for current-borne cues dissolved in the water [209], but no evidence for such a role has been ever been found in turtles [163, 164]. Tracking data on Southern elephant seals have however provided some indirect indications on this line [149].

4.3. Long-Range Navigational Maps? The most comprehensive solution to solve the problem of long-distance oceanic navigation is to rely on some kind of position-fixing mechanism such as large-scale maps, similar to those used by human navigators. In theory, an animal relying on such 
systems (often called "true navigation"; [171]) would be able to establish its position with respect to its home only on the basis of cues detected at its current position [171], and so irrespectively of how it has reached that location, whether by its own motion and/or by the action of external factors such as drift. Large-scale maps thus represent the ultimate navigational tool for long-distance migrants, since they would allow animals to navigate virtually at any location along their journeys, being thus also able to correct for any inaccuracy of their compasses or for natural or experimental displacements. Unfortunately, we know very little about these powerful mechanisms, which have been repeatedly discussed theoretically or invoked to explain the amazing performances of oceanic navigators $[124,125,159,161,210]$, but for which little empirical evidence is available. The most direct way to test reliance on position-fixing mechanisms is to perform displacement experiments, by which animals are translocated away from a location where they reside (typically a breeding area) to test their ability to return to the original home site $[161,211]$. Experiments of this kind involving long-distance translocations have initially been performed on seabirds, where displacements of several hundreds or even thousands of $\mathrm{km}$ were made, without however tracking the birds' movements after release (e.g., $[212,213])$. More recently, the homing behaviour after displacement has been studied in marine turtles and seabirds breeding in oceanic islands, reconstructing the homing paths through satellite telemetry $[55,104,163-168,214]$ or specific direction recorders [215]. Isolated offshore displacements have been done with Jackass penguins (Spheniscus demersus; [216]) and northern elephant seals $[184,186,217]$. The results have shown that displaced animals are mostly able to come back home, even when released from very distant locations [55, 163, 164, 167, 168], although they often follow rather circuitous or nondirect routes [55, 163-166]. In particular, seabirds seem better at compensating displacements than turtles, which sometimes have failed to show any indication of goal-directed navigation $[163,165,214]$ and for which the actual reliance on true navigation has been questioned $[159,163]$. These differences in homing abilities, which are however based upon a limited number of experiments, may be linked to the different medium in which these animals move: flying birds are much more exposed to rapid and substantial displacements due to wind drift than swimming animals, for which currents may possibly produce only limited drift [159]. Hence, birds may have developed much more efficient systems than turtles to deal with unwanted displacements, including experimental ones.

In theory, the best candidates for wide-ranging maps seem to be geomagnetic cues, which are universally accessible and can provide positional information $[188,210]$. Olfactory cues however offer a valid alternative, given their ascertained fundamental role in homing pigeon navigation [218] as well as their importance in many aspects of seabird behaviour [191, 219]. In a series of arena experiments, newborn loggerhead turtles from east Florida beaches have been shown to be sensitive to variations in two geomagnetic parameters, modifying their orientation when presented with specific combinations of magnetic inclination and intensity matching those present at a number of oceanic locations in the North Atlantic Ocean [86, 220, 221]; see also [222]. This orientation behaviour, which evidently derives from an innate mechanism (turtle hatchlings were tested a few hours after their birth, and without having ever been in the sea), has been interpreted as a sort of emergency response that would help the turtles to remain within the currents of the North Atlantic Gyre during their transoceanic developmental migrations, so to avoid potentially lethal waters outside of it $[86,87]$. Such an interpretation has then been supported by simulation studies which highlighted the benefits of such orientation behaviour for migrating neonate turtles [223, 224]. While these findings in turtle hatchlings are often considered to provide important indications for the navigation of adult turtles [225], it rather seems that the recorded hatchling orientation derives from a fundamentally different process from the position-fixing mechanisms proposed for adult turtles $[87,220]$. Hatchlings have no specific target to reach in their developmental migrations and so do not really have to navigate: indeed, their responses are prompted by magnetic conditions that they may never encounter in real life, since it is well possible (and desirable for them!) that they never reach those critical points at the edge of the Gyre in their journeys. As a consequence, their navigational abilities might not encompass a full "knowledge" of their actual position in relation to any target position, and hatchlings might be simply endowed with instructions about where to orient under particular geophysical conditions. In other words, newborn (and perhaps juvenile) turtles might "read" geomagnetic field parameters as signposts rather than as maps (see [226] for a similar distinction in insects), and might move "blindly" along their migratory route [220] unless they encounter a specific signpost telling them where to orient. In any case, these findings are most valuable in showing that turtles do possess a fine magnetic sensitivity and are able to distinguish different values of magnetic inclination and intensity, which are the two parameters most likely involved in the development of geomagnetic maps for large scale navigation $[87,188,210]$.

Empirical data more pertinent with the problem of longdistance navigation have been obtained in another arena experiment, this time performed with juvenile green turtles that were again exposed to magnetic fields differing in their inclination and intensity and matching those of locations away from the test site [227]. The key difference with respect to the hatchling studies is that tested individuals had ended their wandering developmental phase and had settled in their specific neritic foraging areas, which they become faithful to. These turtles therefore had a clearly defined home area to return to, and indeed, when were presented with the artificial magnetic field found in locations about $300 \mathrm{~km}$ North and South of it, they oriented towards home so to correct the "magnetic displacement" they had been subjected to [227]. The interpretation of these findings is unequivocal: these turtles relied on magnetic inclination and intensity to correctly orient towards home, so they used geomagnetic cues to determine their (virtual) position with respect to home. Unfortunately, no other experiments of this kind have been performed recently and so we have no further information 


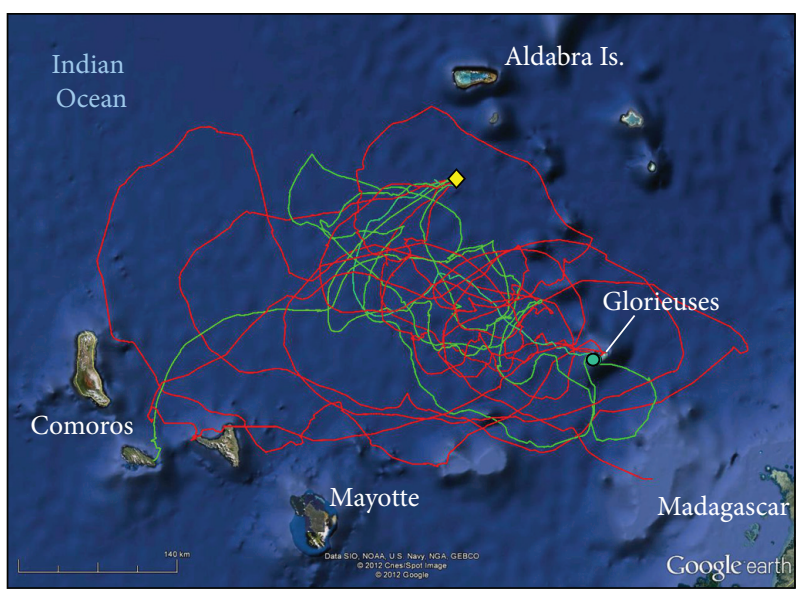

FIGURE 8: Google Earth image showing the homing trips of 8 green sea turtles that were displaced from their breeding site at Glorieuses Is., Eastern Indian Ocean (green dot), to an open-sea release site (yellow diamond), about $150 \mathrm{~km}$ away. Red tracks show the routes of turtles that were disturbed in the perception of the Earth's magnetic field through the application of a magnet on their head. Green tracks refer to undisturbed control turtles. Two turtles failed to return to the home island and moved to Comoros Island or towards Madagascar, while the others homed to Glorieuses, although following very circuitous paths. Data from [55].

on the features of this magnetic navigation ability in green turtles (e.g., whether it also works for displacements over smaller spatial scales or in other directions). This finding, albeit unique, remains the most clear-cut evidence so far available of the turtle ability to rely on a sort of large-scale magnetic map to navigate.

The role of geomagnetic cues in oceanic navigation has been tested also through satellite tracking experiments in field conditions. Ascension Island green turtles were not affected in their postnesting migration by the presence of an altered magnetic field around their body, produced by powerful magnets masking the natural geomagnetic field, showing that geomagnetic cues are not essential to them to accomplish their migration towards Brazil [228]. In successive displacement experiments, the role of geomagnetic cues in the navigation towards a more isolated target than the Brazilian coast was examined by translocating green turtle females nesting on islands in the Mozambique Channel to distant $(>100 \mathrm{~km})$ open sea release sites. Some displaced turtles had a mobile magnet glued to their head, which prevented them to correctly detect the natural magnetic field. In two successive experiments performed in different islands, magnetically treated turtles had worse homing performances than untreated controls, following longer and/more or convoluted routes but being still mostly able to return to the home island after some time (Figure $8 ;[55,166]$ ). These findings revealed the role of geomagnetic information in the homing process of freely moving turtles directed towards isolated targets, although they did not allow to conclude whether the treatment specifically affected a magnetic map or another orientation process mediated by magnetic cues (e.g., a magnetic compass). Experiments involving magnetic manipulations have also been performed on seabirds nesting in isolated oceanic islands, without however showing any effect of the magnetic disturbance: white-chinned petrels (Procellaria aequinoctialis) carrying magnets homed successfully to Possession Island in the Southern Ocean after having been displaced to open sea locations $>300 \mathrm{~km}$ away [168]. Similarly, both Southern Ocean wandering albatrosses and Galapagos waved albatrosses (Phoebastria irrorata) were not affected by magnets attached to their head in finding their island at the end of long-distance foraging trips $[229,230]$.

To summarise, although reliance on position fixing mechanisms would be a crucial tool for oceanic migrants, allowing most of (if not all) the performances described, we still have quite limited evidence supporting their role among long-distance navigators. The best indications come from the findings on birds and turtles showing their ability to compensate for actual or virtual displacements (although with some difficulties in freely-moving turtles), with turtles likely relying on magnetic cues. But these conclusions derive from sparse experiments, that have also highlighted some differences in homing abilities between these two groups still to be explained [159]. On the whole, the most compelling reason to take such GPS-like mechanisms into consideration for open sea navigation comes from the very performances known in oceanic migrants $[124,159]$. It is simply hard to think to any mechanism other than some form of positionfixing that would permit long-distance navigational feats such as those of a shark heading to a specific offshore location (Figure 2) or of a shearwater or a leatherback (Figures 4 and 5) returning to its breeding site after months spent wandering over the ocean. On the other hand, it is reasonable that large-scale maps are not the only system used by longdistance migrants: interestingly, the findings on turtles and birds have been interpreted within a similar conceptual framework, involving a coexistence of different navigational mechanisms acting concurrently or sequentially during goaldirected navigation, being likely active at different spatial scales $[125,159,161]$. Under this scenario, maps (e.g., magnetic or olfactory) may provide animals with general, possibly rather coarse, positional indications, which can then be integrated and/or supplemented with other, more detailed navigational information, such as local beacons [161]. At the present stage it is premature to evaluate whether, and to which extent, such an idea can be extended to the other oceanic navigators, and it can only be hoped that further elements may be collected on this issue in the near future.

\section{Conclusions}

Several techniques are now available to follow oceanic migrants in their long-distance movements and the results obtained have often revealed astonishing feats of migrations. Basin-wide oceanic movements are quite routinely recorded in various animals like sharks, turtles, whales, seals, while many seabirds have been tracked while flying for huge distances in different hemispheres. Unfortunately, experimental data are still scarce for many oceanic wanderers, because of major limitations in the available solutions to track their movements. Ongoing and future technical developments 
in tracking technologies may be most helpful to increase the range of animals suitable to be tracked during their migrations, including those groups that now escape scientific investigations (notably most fish species, and large invertebrates) or are monitored only with great difficulties, such as some fishes and cetaceans.

The wealth of data accumulating on the spatial and ecological features of oceanic migrations do not find correspondence in our knowledge of the orientation and navigation systems accompanying these migratory phenomena. Hopefully researchers will pay more attention in the near future to these aspects, extending to marine animals the current interest and efforts dedicated to the study of animal orientation outside the marine environment. It is envisaged that most fruitful results could be yielded in the near future, for example through specific analyses of the reconstructed migratory routes in relation to specific cues (e.g., magnetic, environmental or oceanographic conditions) or, possibly, through dedicated experimentation aimed at testing specific navigation hypotheses. In this way, it will be hopefully possible to soon shed some light on the behavioural mechanisms underlying these, otherwise mysterious, migratory performances.

\section{Acknowledgments}

Thanks are due to Graeme Hays (University of Swansea, UK) for permission to use his tracking data and to Francesco Bonadonna (CNRS Montpellier, France), David Sims (Marine Biological Association, UK) and Agnes Le Port (University of Auckland) for the pictures used in Figure 1. Resi Mencacci and Daniele Santerini greatly helped in the preparation of the paper.

\section{References}

[1] H. Dingle, Migration, The Biology of Life on the Move, Oxford University Press, New York, NY, USA, 1996.

[2] P. Berthold, Bird Migration: A General Survey, Oxford University Press, New York, NY, USA, 2001.

[3] B. A. Block, I. D. Jonsen, S. J. Jorgensen et al., "Tracking apex marine predator movements in a dynamic ocean," Nature, vol. 475, no. 7354, pp. 86-90, 2011.

[4] P. Luschi, G. C. Hays, and F. Papi, "A review of long-distance movements by marine turtles, and the possible role of ocean currents," Oikos, vol. 103, no. 2, pp. 293-302, 2003.

[5] B. Mate, R. Mesecar, and B. Lagerquist, "The evolution of satellite-monitored radio tags for large whales: one laboratory's experience," Deep-Sea Research Part II, vol. 54, no. 3-4, pp. 224-247, 2007.

[6] B. J. Godley, J. M. Blumenthal, A. C. Broderick et al., "Satellite tracking of sea turtles: where have we been and where do we go next?" Endangered Species Research, vol. 4, no. 1-2, pp. 3-22, 2008.

[7] A. E. Burger and S. A. Shaffer, "Application of tracking and datalogging technology in research and conservation of seabirds," The Auk, vol. 125, pp. 253-264, 2008.

[8] J. Gonzales-Solis and S. A. Shaffer, "Introduction and synthesis: spatial ecology of seabirds at sea," Marine Ecology Progress Series, vol. 391, pp. 117-120, 2009.
[9] N. Hammerschlag, A. J. Gallagher, and D. M. Lazarre, "A review of shark satellite tagging studies," Journal of Experimental Marine Biology and Ecology, vol. 398, no. 1-2, pp. 1-8, 2011.

[10] G. L. Shillinger, H. Bailey, S. J. Bograd et al., "Tagging through the stages: technical and ecological challenges in observing life histories through biologging," Marine Ecology Progress Series, vol. 457, pp. 165-170, 2012.

[11] P. Kanciruk and W. Herrnkind, "Mass migration of spiny lobster, Panulirus argus (Crustacea: Palinuridae): behavior and environmental correlates," Bulletin of Marine Science, vol. 28, pp. 601-623, 1978.

[12] A. M. Adamczewska and S. Morris, "Ecology and behavior of Gecarcoidea natalis, the Christmas Island red crab, during the annual breeding migration," Biological Bulletin, vol. 200, no. 3, pp. 305-320, 2001.

[13] S. Åkesson and A. Hedenström, "How migrants get there: migratory performance and orientation," BioScience, vol. 57, no. 2, pp. 123-133, 2007.

[14] R. T. Cardé and M. A. Willis, "Navigational strategies used by insects to find distant, wind-borne sources of odor," Journal of Chemical Ecology, vol. 34, no. 7, pp. 854-866, 2008.

[15] J. L. DeBose and G. A. Nevitt, "The use of odors at different spatial scales: comparing birds with fish," Journal of Chemical Ecology, vol. 34, no. 7, pp. 867-881, 2008.

[16] C. A. Radford, J. A. Stanley, C. T. Tindle, J. C. Montgomery, and A. G. Jeffs, "Localised coastal habitats have distinct underwater sound signatures," Marine Ecology Progress Series, vol. 401, pp. $21-29,2010$

[17] J. J. Millspaugh and J. M. Marzluff, Radio Tracking and Animal Populations, Academic Press, San Diego, Calif, USA, 2001.

[18] M. R. Heupel, J. M. Semmens, and A. J. Hobday, "Automated acoustic tracking of aquatic animals: scales, design and deployment of listening station arrays," Marine and Freshwater Research, vol. 57, no. 1, pp. 1-13, 2006.

[19] A. B. Meylan, "Sea turtle migration-evidence from tag returns," in Biology and Conservation of Sea Turtles, K. A. Bjorndal, Ed., pp. 91-100, Smithsonian Institution Press, Washington, DC, USA, 1982.

[20] T. P. Quinn and K. W. Myers, "Anadromy and the marine migrations of Pacific salmon and trout: rounsefell revisited," Reviews in Fish Biology and Fisheries, vol. 14, no. 4, pp. 421-442, 2004.

[21] R. Bonfil, M. Meÿer, M. C. Scholl et al., "Transoceanic migration, spatial dynamics, and population linkages of white sharks," Science, vol. 310, no. 5745, pp. 100-103, 2005.

[22] K. Rasmussen, D. M. Palacios, J. Calambokidis et al., "Southern Hemisphere humpback whales wintering off Central America: insights from water temperature into the longest mammalian migration," Biology Letters, vol. 3, no. 3, pp. 302-305, 2007.

[23] P. T. Stevick, M. C. Neves, F. Johansen et al., "A quarter of a world away: female humpback whale moves $10,000 \mathrm{~km}$ between breeding areas," Biology Letters, vol. 7, no. 2, pp. 299-302, 2011.

[24] G. Arnold and H. Dewar, "Electronic tags in marine fisheries research: a 30-year perspective," in Electronic Tagging and Tracking in Marine Fisheries, J. R. Sibert and J. L. Nielsen, Eds., pp. 7-64, Kluwer Academic Publishers, Dordrecht, The Netherlands, 2001.

[25] F. G. Carey and J. V. Scharold, "Movements of blue sharks (Prionace glauca) in depth and course," Marine Biology, vol. 106, no. 3, pp. 329-342, 1990. 
[26] R. W. Brill, D. B. Holts, R. K. C. Chang, S. Sullivan, H. Dewar, and F. G. Carey, "Vertical and horizontal movements of striped marlin (Tetrapturus audax) near the Hawaiian Islands, determined by ultrasonic telemetry, with simultaneous measurement of oceanic currents," Marine Biology, vol. 117, no. 4, pp. 567-574, 1993.

[27] J. M. Semmens, G. T. Pecl, B. M. Gillanders et al., "Approaches to resolving cephalopod movement and migration patterns," Reviews in Fish Biology and Fisheries, vol. 17, no. 2-3, pp. 401-423, 2007.

[28] K. E. Stark, G. D. Jackson, and J. M. Lyle, "Tracking arrow squid movements with an automated acoustic telemetry system," Marine Ecology Progress Series, vol. 299, pp. 167-177, 2005.

[29] G. T. Pecl, S. R. Tracey, J. M. Semmens, and G. D. Jackson, "Use of acoustic telemetry for spatial management of southern calamary Sepioteuthis australis, a highly mobile inshore squid species," Marine Ecology Progress Series, vol. 328, pp. 1-15, 2006.

[30] A. J. Dunstan, P. D. Ward, and N. J. Marshall, "Vertical distribution and migration patterns of Nautilus pompilius," PLoS One, vol. 6, no. 2, Article ID e16311, 2011.

[31] S. K. Hooker and R. W. Baird, "Diving and ranging behaviour of odontocetes: a methodological review and critique," Mammal Review, vol. 31, no. 1, pp. 81-105, 2001.

[32] R. D. Hill, "Theory of geolocation by light levels," in Elephant Seals: Population Ecology, Behavior, and Physiology, B. J. Le Boeuf and R. M. Laws, Eds., pp. 228-237, University of California Press, Berkeley, Calif, USA, 1994.

[33] R. A. Phillips, J. R. D. Silk, J. P. Croxall, V. Afanasyev, and D. R. Briggs, "Accuracy of geolocation estimates for flying seabirds," Marine Ecology Progress Series, vol. 266, pp. 265-272, 2004.

[34] S. G. Wilson, B. S. Stewart, J. J. Polovina, M. G. Meekan, J. D. Stevens, and B. Galuardi, "Accuracy and precision of archival tag data: a multiple-tagging study conducted on a whale shark (Rhincodon typus) in the Indian Ocean," Fisheries Oceanography, vol. 16, no. 6, pp. 547-554, 2007.

[35] E. S. Bridge, K. Thorup, M. S. Bowlin et al., "Technology on the move: recent and forthcoming innovations for tracking migratory birds," BioScience, vol. 61, pp. 689-698, 2011.

[36] S. M. Tomkiewicz, M. R. Fuller, J. G. Kie, and K. K. Bates, "Global positioning system and associated technologies in animal behaviour and ecological research," Philosophical Transactions of the Royal Society B, vol. 365, no. 1550, pp. 2163-2176, 2010.

[37] K. Von Hünerbein, H. J. Hamann, E. Rüter, and W. Wiltschko, "A GPS-based system for recording the flight paths of birds," Naturwissenschaften, vol. 87, no. 6, pp. 278-279, 2000.

[38] I. Steiner, C. Bürgi, S. Werffeli et al., "A GPS logger and software for analysis of homing in pigeons and small mammals," Physiology and Behavior, vol. 71, no. 5, pp. 589-596, 2000.

[39] P. G. Ryan, S. L. Petersen, G. Peters, and D. Grémillet, “GPS tracking a marine predator: the effects of precision, resolution and sampling rate on foraging tracks of African Penguins," Marine Biology, vol. 145, no. 2, pp. 215-223, 2004.

[40] F. Cagnacci, L. Boitani, R. A. Powell, and M. S. Boyce, "Animal ecology meets GPS-based radiotelemetry: a perfect storm of opportunities and challenges," Philosophical Transactions of the Royal Society B, vol. 365, no. 1550, pp. 2157-2162, 2010.

[41] G. Schofield, C. M. Bishop, G. MacLean et al., "Novel GPS tracking of sea turtles as a tool for conservation management," Journal of Experimental Marine Biology and Ecology, vol. 347, no. 1-2, pp. 58-68, 2007.
[42] M. J. Witt, S. Åkesson, A. C. Broderick et al., "Assessing accuracy and utility of satellite-tracking data using Argos-linked FastlocGPS," Animal Behaviour, vol. 80, no. 3, pp. 571-581, 2010.

[43] D. P. Costa, P. W. Robinson, J. P. Y. Arnould et al., "Accuracy of ARGOS locations of pinnipeds at-sea estimated using fastloc GPS," PLoS One, vol. 5, no. 1, Article ID e8677, 2010.

[44] H. Weimerskirch, F. Bonadonna, F. Bailleul, G. Mabille, G. Dell'Omo, and H. P. Lipp, "GPS tracking of foraging albatrosses," Science, vol. 295, no. 5558, p. 1259, 2002.

[45] D. Grémillet, G. Dell'Omo, P. G. Ryan, G. Peters, Y. RopertCoudert, and S. J. Weeks, "Offshore diplomacy, or how seabirds mitigate intra-specific competition: a case study based on GPS tracking of Cape gannets from neighbouring colonies," Marine Ecology Progress Series, vol. 268, pp. 265-279, 2004.

[46] K. M. Hart and K. D. Hyrenbach, "Satellite telemetry of marine megavertebrates: the coming of age of an experimental science," Endangered Species Research, vol. 10, no. 1, pp. 9-20, 2010.

[47] R. B. Boone, S. J. Thirgood, and J. G. C. Hopcraft, "Serengeti wildebeest migratory patterns modeled from rainfall and new vegetation growth," Ecology, vol. 87, no. 8, pp. 1987-1994, 2006.

[48] M. Gschweng, E. K. V. Kalko, U. Querner, W. Fiedler, and P. Berthold, "All across Africa: highly individual migration routes of Eleonora's falcon," Proceedings of the Royal Society B, vol. 275, no. 1653, pp. 2887-2896, 2008.

[49] K. C. Weng, P. C. Castilho, J. M. Morrissette et al., "Satellite tagging and cardiac physiology reveal niche expansion in salmon sharks," Science, vol. 310, no. 5745, pp. 104-106, 2005.

[50] G. C. Hays, S. Åkesson, B. J. Godley, P. Luschi, and P. Santidrian, "The implications of location accuracy for the interpretation of satellite-tracking data," Animal Behaviour, vol. 61, no. 5, pp. 1035-1040, 2001.

[51] M. Biuw, L. Boehme, C. Guinet et al., "Variations in behavior and condition of a Southern Ocean top predator in relation to in situ oceanographic conditions," Proceedings of the National Academy of Sciences of the United States of America, vol. 104, no. 34, pp. 13705-13710, 2007.

[52] O. V. Shpak, R. D. Andrews, D. M. Glazov, D. I. Litovka, R. C. Hobbs, and L. M. Mukhametov, "Seasonal migrations of sea of Okhotsk beluga whales (Delphinapterus leucas) of the SakhalinAmur summer aggregation," Russian Journal of Marine Biology, vol. 36, no. 1, pp. 56-62, 2010.

[53] C. C. Schwartz and S. M. Arthur, "Radiotracking large wilderness mammals: integration of GPS and argostechnology," Ursus, vol. 11, pp. 261-274, 1999.

[54] T. Yasuda and N. Arai, "Fine-scale tracking of marine turtles using GPS-Argos PTTs," Zoological Science, vol. 22, no. 5, pp. 547-553, 2005.

[55] S. Benhamou, J. Sudre, J. Bourjea, S. Ciccione, A. De Santis, and P. Luschi, "The role of geomagnetic cues in green turtle open sea navigation,” PLoS One, vol. 6, Article ID e26672, 2011.

[56] C. E. Kuhn, D. S. Johnson, R. R. Ream, and T. S. Gelatt, "Advances in the tracking of marine species: using GPS locations to evaluate satellite track data and a continuous-time movement model," Marine Ecology Progress Series, vol. 393, pp. 97-109, 2009.

[57] G. Schofield, V. J. Hobson, S. Fossette, M. K. S. Lilley, K. A. Katselidis, and G. C. Hays, "Fidelity to foraging sites, consistency of migration routes and habitat modulation of home range by sea turtles," Diversity and Distributions, vol. 16, no. 5, pp. 840-853, 2010 . 
[58] B. A. Block, H. Dewar, C. Farwell, and E. D. Prince, "A new satellite technology for tracking the movements of Atlantic bluefin tuna," Proceedings of the National Academy of Sciences of the United States of America, vol. 95, no. 16, pp. 9384-9389, 1998.

[59] A. M. Boustany, S. F. Davis, P. Pyle, S. D. Anderson, B. J. Le Boeuf, and B. A. Block, "Expanded niche for white sharks," Nature, vol. 415, no. 6867, pp. 35-36, 2002.

[60] K. Aarestrup, F. Økland, M. M. Hansen et al., "Oceanic spawning migration of the european eel (Anguilla anguilla)," Science, vol. 325, no. 5948, p. 1660, 2009.

[61] G. B. Skomal, S. I. Zeeman, J. H. Chisholm et al., "Transequatorial migrations by basking sharks in the western atlantic ocean," Current Biology, vol. 19, no. 12, pp. 1019-1022, 2009.

[62] A. Le Port, T. Sippel, and J. C. Montgomery, "Observations of mesoscale movements in the short-tailed stingray, Dasyatis brevicaudata from New Zealand using a novel PSAT tag attachment method," Journal of Experimental Marine Biology and Ecology, vol. 359, no. 2, pp. 110-117, 2008.

[63] P. Luschi, G. C. Hays, C. Del Seppia, R. Marsh, and F. Papi, “The navigational feats of green sea turtles migrating from Ascension Island investigated by satellite telemetry," Proceedings of the Royal Society B, vol. 265, no. 1412, pp. 2279-2284, 1998.

[64] G. C. Hays, A. C. Broderick, B. J. Godley et al., "Biphasal longdistance migration in green turtles," Animal Behaviour, vol. 64, no. 6, pp. 895-898, 2002.

[65] G. C. Hays, V. J. Hobson, J. D. Metcalfe, D. Righton, and D. W. Sims, "Flexible foraging movements of leatherback turtles across the North Atlantic ocean," Ecology, vol. 87, no. 10, pp. 2647-2656, 2006.

[66] S. A. Shaffer, Y. Tremblay, H. Weimerskirch et al., "Migratory shearwaters integrate oceanic resources across the Pacific Ocean in an endless summer," Proceedings of the National Academy of Sciences of the United States of America, vol. 103, no. 34, pp. 12799-12802, 2006.

[67] B. J. Le Boeuf, D. E. Crocker, D. P. Costa, S. B. Blackwell, P. M. Webb, and D. S. Houser, "Foraging ecology of northern elephant seals," Ecological Monographs, vol. 70, no. 3, pp. 353-382, 2000.

[68] E. G. Dawe, P. C. Beck, H. J. Drew, and G. H. Winters, "Longdistance migration of a short-finned squid, lIIex iIIecebrosus," Journal of Northwest Atlantic Fishery Science, vol. 2, pp. 75-76, 1981.

[69] J. C. Groeneveld and G. M. Branch, "Long-distance migration of South African deep-water rock lobster Palinurus gilchristi," Marine Ecology Progress Series, vol. 232, pp. 225-238, 2002.

[70] W. F. Gilly, U. Markaida, C. H. Baxter et al., "Vertical and horizontal migrations by the jumbo squid Dosidicus gigas revealed by electronic tagging," Marine Ecology Progress Series, vol. 324, pp. 1-17, 2006.

[71] G. P. Arnold, "Fish migration, horizontal," in Encyclopedia of Ocean Sciences, J. Steele, S. Thorpe, and K. Turekian, Eds., pp. 947-955, Academic Press, London, UK, 2001.

[72] V. J. T. van Ginneken and G. E. Maes, "The European eel (Anguilla anguilla, Linnaeus), its lifecycle, evolution and reproduction: a literature review," Reviews in Fish Biology and Fisheries, vol. 15, no. 4, pp. 367-398, 2005.

[73] B. A. Block, H. Dewar, S. B. Blackwell et al., "Migratory movements, depth preferences, and thermal biology of Atlantic bluefin tuna," Science, vol. 293, no. 5533, pp. 1310-1314, 2001.

[74] E. Hunter, J. D. Metcalfe, B. H. Holford, and G. P. Arnold, "Geolocation of free-ranging fish on the European continental shelf as determined from environmental variables II. Reconstruction of plaice ground tracks," Marine Biology, vol. 144, no. 4, pp. 787-798, 2004.

[75] S. A. Eckert and B. S. Stewart, "Telemetry and satellite tracking of whale sharks, Rhincodon typus, in the Sea of Cortez, Mexico, and the north Pacific Ocean," Environmental Biology of Fishes, vol. 60, no. 1-3, pp. 299-308, 2001.

[76] M. A. Gore, D. Rowat, J. Hall, F. R. Gell, and R. F. Ormond, "Transatlantic migration and deep mid-ocean diving by basking shark," Biology Letters, vol. 4, no. 4, pp. 395-398, 2008.

[77] K. C. Weng, D. G. Foley, J. E. Ganong, C. Perle, G. L. Shillinger, and B. A. Block, "Migration of an upper trophic level predator, the salmon shark Lamna ditropis, between distant ecoregions," Marine Ecology Progress Series, vol. 372, pp. 253-264, 2008.

[78] S. J. Jorgensen, C. A. Reeb, T. K. Chapple et al., "Philopatry and migration of Pacific white sharks," Proceedings of the Royal Society B, vol. 277, no. 1682, pp. 679-688, 2010.

[79] D. W. Sims, N. Queiroz, T. K. Doyle, J. D. R. Houghton, and G. C. Hays, "Satellite tracking of the World's largest bony fish, the ocean sunfish (Mola mola L.) in the North East Atlantic," Journal of Experimental Marine Biology and Ecology, vol. 370, no. 1-2, pp. 127-133, 2009.

[80] J. C. Holdsworth, T. J. Sippel, and B. A. Block, "Near real time satellite tracking of striped marlin (Kajikia audax) movements in the Pacific Ocean," Marine Biology, vol. 156, no. 3, pp. 505-514, 2009.

[81] H. Dewar, T. Thys, S. L. H. Teo et al., "Satellite tracking the world's largest jelly predator, the ocean sunfish, Mola mola, in the Western Pacific," Journal of Experimental Marine Biology and Ecology, vol. 393, no. 1-2, pp. 32-42, 2010.

[82] B. A. Block, S. L. H. Teo, A. Walli et al., "Electronic tagging and population structure of Atlantic bluefin tuna," Nature, vol. 434, no. 7037, pp. 1121-1127, 2005.

[83] S. L. H. Teo, A. Boustany, H. Dewar et al., "Annual migrations, diving behavior, and thermal biology of Atlantic bluefin tuna, Thunnus thynnus, on their Gulf of Mexico breeding grounds," Marine Biology, vol. 151, no. 1, pp. 1-18, 2007.

[84] J. A. Musick and C. J. Limpus, "Habitat utilization and migration in juvenile sea turtles," in The Biology of Sea Turtles, P. L. Lutz and J. A. Musick, Eds., pp. 137-164, CRC Press, Boca Raton, Fla, USA, 1997.

[85] A. Southwood and L. Avens, "Physiological, behavioral, and ecological aspects of migration in reptiles," Journal of Comparative Physiology B, vol. 180, no. 1, pp. 1-23, 2009.

[86] K. J. Lohmann, S. D. Cain, S. A. Dodge, and C. M. F. Lohmann, "Regional magnetic fields as navigational markers for sea turtles," Science, vol. 294, no. 5541, pp. 364-366, 2001.

[87] K. J. Lohmann and C. M. F. Lohmann, "Sea turtles,lobsters, and oceanic magnetic maps," Marine and Freshwater Behaviour and Physiology, vol. 39, no. 1, pp. 49-64, 2006.

[88] W. J. Nichols, A. Resendiz, J. A. Seminoff, and B. Resendiz, "Transpacific migration of a loggerhead turtle monitored by satellite telemetry," Bulletin of Marine Science, vol. 67, no. 3, pp. 937-947, 2000.

[89] A. L. McCarthy, S. Heppell, F. Royer, C. Freitas, and T. Dellinger, "Identification of likely foraging habitat of pelagic loggerhead sea turtles (Caretta caretta) in the North Atlantic through analysis of telemetry track sinuosity," Progress in Oceanography, vol. 86, no. 1-2, pp. 224-231, 2010.

[90] K. L. Eckert, B. P. Wallace, J. G. Frazier, S. A. Eckert, and P. C. H. Pritchard, "Synopsis of the biological data on the leatherback 
sea turtle (Dermochelys coriacea)," Biological Technical BTPR4015-2012, US Department of Interior, Fish and Wildlife Service, Washington, DC, USA, 2012.

[91] H. Hatase, N. Takai, Y. Matsuzawa et al., "Size-related differences in feeding habitat use of adult female loggerhead turtles Caretta caretta around Japan determined by stable isotope analyses and satellite telemetry," Marine Ecology Progress Series, vol. 233, pp. 273-281, 2002.

[92] L. A. Hawkes, A. C. Broderick, M. S. Coyne et al., "Phenotypically linked dichotomy in sea turtle foraging requires multiple conservation approaches," Current Biology, vol. 16, no. 10, pp. 990-995, 2006.

[93] C. M. McClellan and A. J. Read, "Complexity and variation in loggerhead sea turtle life history," Biology letters, vol. 3, no. 6, pp. 592-594, 2007.

[94] P. Casale, G. Abbate, D. Freggi, N. Conte, M. Oliverio, and R. Argano, "Foraging ecology of loggerhead sea turtles Caretta caretta in the central Mediterranean Sea: evidence for a relaxed life history model," Marine Ecology Progress Series, vol. 372, pp. 265-276, 2008.

[95] B. W. Bowen and S. A. Karl, "Population genetics and phylogeography of sea turtles," Molecular Ecology, vol. 16, no. 23, pp. 4886-4907, 2007.

[96] C. J. Limpus, J. D. Miller, C. J. Parmenter, D. Reimer, N. McLachlan, and R. Webb, "Migration of green (Chelonia mydas) and loggerhead (Caretta caretta) turtles to and from eastern Australian rookeries," Wildlife Research, vol. 19, no. 3, pp. 347-358, 1992.

[97] A. C. Broderick, M. S. Coyne, W. J. Fuller, F. Glen, and B. J. Godley, "Fidelity and over-wintering of sea turtles," Proceedings of the Royal Society B, vol. 274, no. 1617, pp. 1533-1538, 2007.

[98] G. C. Hays, J. D. R. Houghton, and A. E. Myers, "Endangered species: Pan-Atlantic leatherback turtle movements," Nature, vol. 429, no. 6991, article 522, 2004.

[99] P. Luschi, J. R. E. Lutjeharms, P. Lambardi, R. Mencacci, G. R. Hughes, and G. C. Hays, "A review of migratory behaviour of sea turtles off southeastern Africa," South African Journal of Science, vol. 102, no. 1-2, pp. 51-58, 2006.

[100] P. T. Plotkin, "Nomadic behaviour of the highly migratory olive ridley sea turtle Lepidochelys olivacea in the eastern tropical Pacific Ocean," Endangered Species Research, vol. 13, no. 1, pp. 33-40, 2010.

[101] H. Bailey, S. R. Benson, G. Shillinger et al., "Identification of distinct movement patterns in Pacific leatherback turtle populations influenced by ocean conditions," Ecological Applications, vol. 22, pp. 735-747, 2012.

[102] J. A. Seminoff, P. Zárate, M. Coyne et al., "Post-nesting migrations of Galápagos green turtles Chelonia mydas in relation to oceanographic conditions: integrating satellite telemetry with remotely sensed ocean data," Endangered Species Research, vol. 4, no. 1-2, pp. 57-72, 2008.

[103] G. H. Balazs, P. Craig, B. R. Winton, and R. K. Miya, "Satellite telemetry of green turtles nesting at French Frigate Shoals, Hawaii, and Rose Atoll, American Samoa," in Proceedings of the 14th Annual Symposium on Sea Turtle Biology and Conservation, K. A. Bjorndal, A. B. Bolten, D. A. Johnson, and P. J. Eliazar, Eds., NOAA Tech. Memo. NMFS-SEFSC-351, pp. 184-187, 1994.

[104] P. Luschi, F. Papi, H. C. Liew, E. H. Chan, and F. Bonadonna, "Long-distance migration and homing after displacement in the green turtle (Chelonia mydas): a satellite tracking study," Journal of Comparative Physiology A, vol. 178, no. 4, pp. 447-452, 1996.
[105] P. Craig, D. Parker, R. Brainard, M. Rice, and G. Balazs, "Migrations of green turtles in the central South Pacific," Biological Conservation, vol. 116, no. 3, pp. 433-438, 2004.

[106] B. J. Godley, A. C. Broderick, and G. C. Hays, "Nesting of green turtles (Chelonia mydas) at Ascension Island, South Atlantic," Biological Conservation, vol. 97, no. 2, pp. 151-158, 2001.

[107] J. A. Mortimer and A. Carr, "Reproduction and migrations of the Ascension Island green turtle (Chelonia mydas)," Copeia, pp. 103-113, 1987.

[108] C. Darwin, "Perception in the lower animals," Nature, vol. 7, no. 176, p. 360, 1873.

[109] J. A. Horrocks, L. A. Vermeer, B. Krueger, M. Coyne, B. A. Schroeder, and G. H. Balazs, "Migration routes and destination characteristics of post-nesting hawksbill turtles satellite-tracked from Barbados, West Indies," Chelonian Conservation and Biology, vol. 4, no. 1, pp. 107-114, 2001.

[110] C. Girard, A. D. Tucker, and B. Calmettes, "Post-nesting migrations of loggerhead sea turtles in the Gulf of Mexico: dispersal in highly dynamic conditions," Marine Biology, vol. 156, no. 9, pp. 1827-1839, 2009.

[111] L. A. Hawkes, J. Tomas, O. Revuelta et al., "Migratory patterns in hawksbill turtles described by satellite tracking," Marine Ecology Progress Series, vol. 461, pp. 223-232, 2012.

[112] G. L. Shillinger, D. M. Palacios, H. Bailey et al., "Persistent leatherback turtle migrations present opportunities for conservation," PLoS Biology, vol. 6, no. 7, article e171, 2008.

[113] S. R. Benson, T. Eguchi, D. G. Foley et al., "Large-scale movements and high-use areas of western Pacific leatherback turtles, Dermochelys coriacea," Ecosphere, vol. 2, no. 7, article 84, 2011.

[114] M. J. Witt, E. A. Bonguno, A. C. Broderick et al., "Tracking leatherback turtles from the world's largest rookery: assessing threats across the South Atlantic," Proceedings of the Royal Society B, vol. 278, no. 1716, pp. 2338-2347, 2011.

[115] P. H. Dutton, B. W. Bowen, D. W. Owens, A. Barragan, and S. K. Davis, "Global phylogeography of the leatherback turtle (Dermochelys coriacea)," Journal of Zoology, vol. 248, no. 3, pp. 397-409, 1999.

[116] A. Sale and P. Luschi, "Navigational challenges in the oceanic migrations of leatherback sea turtles," Proceedings of the Royal Society B, vol. 276, no. 1674, pp. 3737-3745, 2009.

[117] P. Jouventin and H. Weimerskirch, "Satellite tracking of Wandering albatrosses," Nature, vol. 343, no. 6260, pp. 746-748, 1990.

[118] P. Jouventin, D. Capdeville, F. Cuenotchaillet, and C. Boiteau, "Exploitation of pelagic resources by a non-flying seabird-satellite tracking of the king penguin throughout the breeding cycle," Marine Ecology Progress Series, vol. 106, no. 1-2, pp. 11-20, 1994.

[119] K. Pütz, R. J. Ingham, and J. G. Smith, "Satellite tracking of the winter migration of Magellanic Penguins Spheniscus magellanicus breeding in the Falkland Islands," Ibis, vol. 142, no. 4, pp. 614-622, 2000.

[120] H. Weimerskirch, M. Salamolard, F. Sarrazin, and P. Jouventin, "Foraging strategy of wandering albatrosses through the breeding-season-a study using satellite telemetry," Auk, vol. 110, pp. 325-342, 1993.

[121] H. Weimerskirch, C. P. Doncaster, and F. Cuenot-Chaillet, "Pelagic seabirds and the marine environment-foraging patterns of wandering albatrosses in relation to prey availability and distribution," Proceedings of the Royal Society B, vol. 255, no. 1343 , pp. 91-97, 1994. 
[122] E. T. Kai, V. Rossi, J. Sudre et al., “Top marine predators track Lagrangian coherent structures," Proceedings of the National Academy of Sciences of the United States of America, vol. 106, no. 20, pp. 8245-8250, 2009.

[123] B. J. McConnell, C. Chambers, and M. A. Fedak, "Foraging ecology of southern elephant seals in relation to the bathymetry and productivity of the Southern Ocean," Antarctic Science, vol. 4, no. 4, pp. 393-398, 1992.

[124] F. Papi and P. Luschi, "Pinpointing "Isla Meta": the case of sea turtles and albatrosses," Journal of Experimental Biology, vol. 199, no. 1, pp. 65-71, 1996.

[125] F. Bonadonna, S. Benhamou, and P. Jouventin, "Orientation in, "featureless" environments: the extreme case of pelagic birds", in Avian Migration, P. Berthold, E. Gwinner, and E. Sonnenschein, Eds., pp. 367-377, Springer, Berlin, Germany, 2003.

[126] H. Weimerskirch and R. P. Wilson, "Oceanic respite for wandering albatrosses,” Nature, vol. 406, no. 6799, pp. 955-956, 2000.

[127] R. M. Suryan, F. Sato, G. R. Balogh, K. David Hyrenbach, P. R. Sievert, and K. Ozaki, "Foraging destinations and marine habitat use of short-tailed albatrosses: a multi-scale approach using first-passage time analysis," Deep-Sea Research Part II, vol. 53, no. 3-4, pp. 370-386, 2006.

[128] J. P. Croxall, J. R. D. Silk, R. A. Phillips, V. Afanasyev, and D. R. Briggs, "Global circumnavigations: tracking year-round ranges of nonbreeding albatrosses," Science, vol. 307, no. 5707, pp. 249-250, 2005.

[129] R. A. Phillips, J. R. D. Silk, J. P. Croxall, V. Afanasyev, and V. J. Bennett, "Summer distribution and migration of nonbreeding albatrosses: individual consistencies and implications for conservation," Ecology, vol. 86, no. 9, pp. 2386-2396, 2005.

[130] A. Hedd, W. A. Montevecchi, H. Otley, R. A. Phillips, and D. A. Fifield, "Trans-equatorial migration and habitat use by sooty shearwaters Puffinus griseus from the South Atlantic during the nonbreeding season," Marine Ecology Progress Series, vol. 449, pp. 277-290, 2012.

[131] J. González-Solís, J. P. Croxall, D. Oro, and X. Ruiz, “Transequatorial migration and mixing in the wintering areas of a pelagic seabird," Frontiers in Ecology and the Environment, vol. 5, no. 6, pp. 297-301, 2007.

[132] T. Guilford, J. Meade, J. Willis et al., "Migration and stopover in a small pelagic seabird, the Manx shearwater Puffinus puffinus: insights from machine learning," Proceedings of the Royal Society $B$, vol. 276, no. 1660, pp. 1215-1223, 2009.

[133] M. P. Dias, J. P. Granadeiro, R. A. Phillips, H. Alonso, and P. Catry, "Breaking the routine: individual Cory's shearwaters shift winter destinations between hemispheres and across Ocean basins," Proceedings of the Royal Society B, vol. 278, no. 1713, pp. 1786-1793, 2010.

[134] M. Kopp, H.-U. Peter, O. Mustafa et al., "South polar skuas from a single breeding population overwinter in different oceans though show similar migration patterns," Marine Ecology Progress Series, vol. 435, pp. 263-267, 2011.

[135] C. Egevang, I. J. Stenhouse, R. A. Phillips, A. Petersen, J. W. Fox, and J. R. D. Silk, "Tracking of Arctic terns Sterna paradisaea reveals longest animal migration," Proceedings of the National Academy of Sciences of the United States of America, vol. 107, no. 5, pp. 2078-2081, 2010.

[136] Á. M. Felicísimo, J. Muñoz, and J. González-Solis, "Ocean surface winds drive dynamics of transoceanic aerial movements," PLoS One, vol. 3, no. 8, Article ID e2928, 2008.

[137] R. E. Gill, T. L. Tibbitts, D. C. Douglas et al., "Extreme endurance flights by landbirds crossing the Pacific Ocean: ecological corridor rather than barrier?" Proceedings of the Royal Society B, vol. 276, no. 1656, pp. 447-457, 2009.

[138] J. R. Wilson, S. Nebel, and C. D. T. Minton, "Migration ecology and morphometrics of two Bar-tailed Godwit populations in Australia," Emu, vol. 107, no. 4, pp. 262-274, 2007.

[139] J. F. Schreer, K. M. Kovacs, and R. J. O’Hara Hines, "Comparative diving patterns of pinnipeds and seabirds," Ecological Monographs, vol. 71, no. 1, pp. 137-162, 2001.

[140] F. Bonadonna, M. A. Lea, O. Dehorter, and C. Guinet, "Foraging ground fidelity and route-choice tactics of a marine predator: the Antarctic fur seal Arctocephalus gazella," Marine Ecology Progress Series, vol. 223, pp. 287-297, 2001.

[141] D. Thompson, S. E. W. Moss, and P. Lovell, "Foraging behaviour of South American fur seals Arctocephalus australis: extracting fine scale foraging behaviour from satellite tracks," Marine Ecology Progress Series, vol. 260, pp. 285-296, 2003.

[142] F. Bailleul, C. Cotté, and C. Guinet, "Mesoscale eddies as foraging area of a deep-diving predator, the southern elephant seal," Marine Ecology Progress Series, vol. 408, pp. 251-264, 2010.

[143] A. M. M. Baylis, "Individual foraging site fidelity in lactating New Zealand fur seals: continental shelf vs. oceanic habitats," Marine Mammal Science, vol. 28, pp. 276-294, 2012.

[144] B. W. Robson, M. E. Goebel, J. D. Baker et al., "Separation of foraging habitat among breeding sites of a colonial marine predator, the northern fur seal (Callorhinus ursinus)," Canadian Journal of Zoology, vol. 82, no. 1, pp. 20-29, 2004.

[145] B. L. Chilvers, "Foraging site fidelity of lactating New Zealand sea lions," Journal of Zoology, vol. 276, no. 1, pp. 28-36, 2008.

[146] C. Campagna, A. R. Piola, M. Rosa Marin, M. Lewis, and T. Fernández, "Southern elephant seal trajectories, fronts and eddies in the Brazil/Malvinas Confluence," Deep-Sea Research Part I, vol. 53, no. 12, pp. 1907-1924, 2006.

[147] B. J. McConnell and M. A. Fedak, "Movements of southern elephant seals," Canadian Journal of Zoology, vol. 74, no. 8, pp. 1485-1496, 1996.

[148] T. R. Loughlin, W. J. Ingraham, N. Baba, and B. W. Robson, "Use of a surface-current model and satellite telemetry to assess marine mammal movements in the Bering Sea," in Dynamics of the Bering Sea, T. R. Loughlin and K. Ohtani, Eds., pp. 615-630, University of Alaska Sea Grant AK-SG-99-03, Fairbanks, USA, 1999.

[149] B. McConnell, M. Fedak, H. R. Burton, G. H. Engelhard, and P. J. H. Reijnders, "Movements and foraging areas of naïve, recently weaned southern elephant seal pups," Journal of Animal Ecology, vol. 71, no. 1, pp. 65-78, 2002.

[150] R. R. Ream, J. T. Sterling, and T. R. Loughlin, "Oceanographic features related to northern fur seal migratory movements," Deep-Sea Research Part II, vol. 52, no. 5-6, pp. 823-843, 2005.

[151] B. S. Stewart and R. L. DeLong, "Double migrations of the northern elephant seal, Mirounga angustirostris," Journal of Mammalogy, vol. 76, no. 1, pp. 196-205, 1995.

[152] C. Pomilla and H. C. Rosenbaum, "Against the current: an interoceanic whale migration event," Biology Letters, vol. 1, no. 4, pp. 476-479, 2005.

[153] H. Bailey, B. R. Mate, D. M. Palacios, L. Irvine, S. J. Bograd, and D. P. Costa, "Behavioural estimation of blue whale movements in the Northeast Pacific from state-space model analysis of satellite tracks," Endangered Species Research, vol. 10, no. 1, pp. 93-106, 2010. 
[154] R. S. Wells, H. L. Rhinehart, P. Cunningham et al., "Long distance offshore movements of bottlenose dolphins," Marine Mammal Science, vol. 15, no. 4, pp. 1098-1114, 1999.

[155] J. W. Durban and R. L. Pitman, "Antarctic killer whales make rapid, round-trip movements to subtropical waters: evidence for physiological maintenance migrations?" Biology Letters, vol. 8, no. 2, pp. 274-277, 2012.

[156] B. A. Lagerquist, B. R. Mate, J. G. Ortega-Ortiz, M. Winsor, and J. Urbán-Ramirez, "Migratory movements and surfacing rates of humpback whales (Megaptera novaeangliae) satellite tagged at Socorro Island, Mexico," Marine Mammal Science, vol. 24, no. 4, pp. 815-830, 2008.

[157] C. Garrigue, A. N. Zerbini, Y. Geyer, M. P. Heide-Jørgensen, W. Hanaoka, and P. Clapham, "Movements of satellite-monitored humpback whales from new caledonia," Journal of Mammalogy, vol. 91, no. 1, pp. 109-115, 2010.

[158] T. W. Horton, R. N. Holdaway, A. N. Zerbini et al., "Straight as an arrow: humpback whales swim constant course tracks during long-distance migration," Biology Letters, vol. 7, pp. 674-679, 2011.

[159] V. P. Bingman and K. Cheng, "Mechanisms of animal global navigation: comparative perspectives and enduring challenges," Ethology Ecology and Evolution, vol. 17, no. 4, pp. 295-318, 2005.

[160] K. J. Lohmann, C. M. F. Lohmann, and C. S. Endres, "The sensory ecology of ocean navigation," Journal of Experimental Biology, vol. 211, no. 11, pp. 1719-1728, 2008.

[161] K. J. Lohmann, P. Luschi, and G. C. Hays, "Goal navigation and island-finding in sea turtles," Journal of Experimental Marine Biology and Ecology, vol. 356, no. 1-2, pp. 83-95, 2008.

[162] F. Papi, P. Luschi, E. Crosio, and G. R. Hughes, "Satellite tracking experiments on the navigational ability and migratory behaviour of the loggerhead turtle Caretta caretta," Marine Biology, vol. 129, no. 2, pp. 215-220, 1997.

[163] P. Luschi, S. Åkesson, A. C. Broderick et al., "Testing the navigational abilities of ocean migrants: displacement experiments on green sea turtles (Chelonia mydas)," Behavioral Ecology and Sociobiology, vol. 50, no. 6, pp. 528-534, 2001.

[164] C. Girard, J. Sudre, S. Benhamou, D. Roos, and P. Luschi, "Homing in green turtles Chelonia mydas: oceanic currents act as a constraint rather than as an information source," Marine Ecology Progress Series, vol. 322, pp. 281-289, 2006.

[165] G. C. Hays, S. Åkesson, A. C. Broderick et al., "Island-finding ability of marine turtles," Proceedings of the Royal Society B, vol. 270, supplement, pp. S5-S7, 2003.

[166] P. Luschi, S. Benhamou, C. Girard et al., "Marine turtles use geomagnetic cues during open-sea homing," Current Biology, vol. 17, no. 2, pp. 126-133, 2007.

[167] S. Benhamou, J. Bried, F. Bonadonna, and P. Jouventin, "Homing in pelagic birds: a pilot experiment with white-chinned petrels released in the open sea," Behavioural Processes, vol. 61, no. 1-2, pp. 95-100, 2003.

[168] S. Benhamou, F. Bonadonna, and P. Jouventin, "Successful homing of magnet-carrying white-chinned petrels released in the open sea," Animal Behaviour, vol. 65, no. 4, pp. 729-734, 2003.

[169] S. Benhamou, "Orientation and navigation," in Encyclopedia of Behavioral Neuroscience, G. F. Koob, M. Le Moal, and R. F. Thompson, Eds., vol. 2, pp. 497-503, Academic Press, Oxford, UK, 2010.
[170] G. Kramer, "Long-distance orientation," in Biology and Comparative Physiology in Birds, A. J. Marshall, Ed., pp. 341-371, Academic Press, New York, NY, USA, 1961.

[171] F. Papi, "Navigation of marine, freshwater and coastal animals: concepts and current problems," Marine and Freshwater Behaviour and Physiology, vol. 39, no. 1, pp. 3-12, 2006.

[172] K. J. Lohmann, "Magnetic orientation by hatchling loggerhead sea turtles (Caretta caretta)," Journal of Experimental Biology, vol. 155, pp. 37-49, 1991.

[173] K. J. Lohmann and C. M. F. Lohmann, "A light-independent magnetic compass in the leatherback sea turtle," The Biological Bulletin, vol. 185, pp. 149-151, 1993.

[174] P. Light, M. Salmon, and K. J. Lohmann, "Geomagnetic orientation of loggerhead sea turtles: evidence for an inclination compass," The Journal of Experimental Biology, vol. 182, pp. $1-10,1993$.

[175] L. Avens and K. J. Lohmann, "Use of multiple orientation cues by juvenile loggerhead sea turtles Caretta caretta," Journal of Experimental Biology, vol. 206, no. 23, pp. 4317-4325, 2003.

[176] C. R. Mott and M. Salmon, "Sun compass orientation by juvenile Green sea turtles (Chelonia mydas)," Chelonian Conservation and Biology, vol. 10, no. 1, pp. 73-81, 2011.

[177] T. P. Quinn, "Evidence for celestial and magnetic compass orientation in lake migrating sockeye salmon fry," Journal of Comparative Physiology A, vol. 137, no. 3, pp. 243-248, 1980.

[178] P. B. Taylor, "Experimental evidence for geomagnetic orientation in juvenile salmon, Oncorhynchus tschawytscha Walbaum," Journal of Fish Biology, vol. 28, no. 5, pp. 607-623, 1986.

[179] A. P. Klimley, "Highly directional swimming by scalloped hammerhead sharks, Sphyrna lewini, and subsurface irradiance, temperature, bathymetry, and geomagnetic field," Marine Biology, vol. 117, no. 1, pp. 1-22, 1993.

[180] F. Papi, H. C. Liew, P. Luschi, and E. H. Chan, "Long-range migratory travel of a green turtle tracked by satellite: evidence for navigational ability in the open sea," Marine Biology, vol. 122, no. 2, pp. 171-175, 1995.

[181] P. A. Prince, A. G. Wood, T. Barton, and J. P. Croxall, "Satellite tracking of wandering albatrosses (Diomedea exulans) in the South Atlantic," Antarctic Science, vol. 4, no. 1, pp. 31-36, 1992.

[182] P. Gaspar, J. Y. Georges, S. Fossette, A. Lenoble, S. Ferraroli, and Y. Le Maho, "Marine animal behaviour: neglecting ocean currents can lead us up the wrong track," Proceedings of the Royal Society B, vol. 273, no. 1602, pp. 2697-2702, 2006.

[183] J. W. Chapman, R. H. G. Klaassen, V. A. Drake et al., "Animal orientation strategies for movement in flows," Current Biology, vol. 21, pp. R861-R870, 2011.

[184] R. W. Davis, L. A. Fuiman, T. M. Williams, and B. J. Le Boeuf, "Three-dimensional movements and swimming activity of a northern elephant seal," Comparative Biochemistry and Physiology, vol. 129, no. 4, pp. 759-770, 2001.

[185] T. Narazaki, K. Sato, K. J. Abernathy, G. J. Marshall, and N. Miyazaki, "Sea turtles compensate deflection of heading at the sea surface during directional travel," Journal of Experimental Biology, vol. 212, no. 24, pp. 4019-4026, 2009.

[186] M. Matsumura, Y. Y. Watanabe, P. W. Robinson, P. J. O. Miller, D. P. Costa, and N. Miyazaki, "Underwater and surface behavior of homing juvenile northern elephant seals," Journal of Experimental Biology, vol. 214, no. 4, pp. 629-636, 2011.

[187] A. Yano, M. Ogura, A. Sato et al., "Effect of modified magnetic field on the ocean migration of maturing chum salmon, Oncorhynchus keta," Marine Biology, vol. 129, no. 3, pp. 523-530, 1997. 
[188] K. J. Lohmann, C. M. F. Lohmann, and N. F. Putman, "Magnetic maps in animals: nature's GPS," Journal of Experimental Biology, vol. 210, no. 21, pp. 3697-3705, 2007.

[189] T. S. Collett and M. Collett, "Animal navigation: following signposts in the sea," Current Biology, vol. 21, pp. R843-R846, 2011.

[190] G. A. Nevitt and F. Bonadonna, "Sensitivity to dimethyl sulphide suggests a mechanism for olfactory navigation by seabirds," Biology Letters, vol. 1, no. 3, pp. 303-305, 2005.

[191] G. A. Nevitt, "Sensory ecology on the high seas: the odor world of the procellariiform seabirds," Journal of Experimental Biology, vol. 211, no. 11, pp. 1706-1713, 2008.

[192] S. Kowalewsky, M. Dambach, B. Mauck, and G. Dehnhardt, "High olfactory sensitivity for dimethyl sulphide in harbour seals," Biology Letters, vol. 2, no. 1, pp. 106-109, 2006.

[193] K. L. B. Wright, L. Pichegru, and P. G. Ryan, "Penguins are attracted to dimethyl sulphide at sea," Journal of Experimental Biology, vol. 214, no. 15, pp. 2509-2511, 2011.

[194] C. S. Endres and K. J. Lohmann, "Perception of dimethyl sulfide (DMS) by loggerhead sea turtles: a possible mechanism for locating high-productivity oceanic regions for foraging," The Journal of Experimental Biology, vol. 215, pp. 3535-3538, 2012.

[195] A. Carr, The Sea Turtle, University of Texas Press, Austin, Tex, USA, 1984.

[196] M. Muller and R. Wehner, "The hidden spiral: systematic search and path integration in desert ants, Cataglyphis fortis," Journal of Comparative Physiology A, vol. 175, no. 5, pp. 525-530, 1994.

[197] P. Berthold, "Genetic basis and evolutionary aspects of bird migration," Advances in the Study of Behavior, vol. 33, pp. 175-229, 2003.

[198] R. Wehner and M. V. Srinivasan, "Path integration in insects," in The Neurobiology of Spatial Behaviour, K. J. Jeffery, Ed., pp. 9-30, Oxford University Press, Oxford, UK, 2003.

[199] S. Benhamou, J. P. Sauve, and P. Bovet, "Spatial memory in large scale movements: efficiency and limitation of the egocentric coding process," Journal of Theoretical Biology, vol. 145, no. 1, pp. 1-12, 1990.

[200] W. J. Richardson, "Wind and orientation of migrating birds: a review," in Orientation in Birds, P. Berthold, Ed., pp. 226-249, Birkhauser, Basel, Switzerland, 1991.

[201] S. Fossette, N. F. Putman, K. J. Lohmann, R. Marsh, and G. C. Hays, "A biologist's guide to assessing ocean currents: a review," Marine Ecology Progress Series, vol. 457, pp. 285-301, 2012.

[202] D. C. Nel, J. R. E. Lutjeharms, E. A. Pakhomov, I. J. Ansorge, P. G. Ryan, and N. T. W. Klages, "Exploitation of mesoscale oceanographic features by grey-headed albatross Thalassarche chrysostoma in the southern Indian Ocean," Marine Ecology Progress Series, vol. 217, pp. 15-26, 2001.

[203] P. Luschi, A. Sale, R. Mencacci, G. R. Hughes, J. R. E. Lutjeharms, and F. Papi, "Current transport of leatherback sea turtles (Dermochelys coriacea) in the ocean," Proceedings of the Royal Society B, vol. 270, supplement 2, pp. S129-S132, 2003.

[204] P. Lambardi, J. R. E. Lutjeharms, R. Mencacci, G. C. Hays, and P. Luschi, "Influence of ocean currents on long-distance movement of leatherback sea turtles in the Southwest Indian Ocean," Marine Ecology Progress Series, vol. 353, pp. 289-301, 2008.

[205] S. Fossette, V. J. Hobson, C. Girard et al., "Spatio-temporal foraging patterns of a giant zooplanktivore, the leatherback turtle," Journal of Marine Systems, vol. 81, no. 3, pp. 225-234, 2010 .
[206] J. Sudre and R. A. Morrow, "Global surface currents: a highresolution product for investigating ocean dynamics," Ocean Dynamics, vol. 58, no. 2, pp. 101-118, 2008.

[207] S. Galli, P. Gaspar, S. Fossette et al., "Orientation of migrating leatherback turtles in relation to ocean currents," Animal Behaviour, vol. 84, no. 6, pp. 1491-1500, 2012.

[208] C. S. Endres, N. F. Putman, and K. J. Lohmann, "Perception of airborne odors by loggerhead sea turtles," Journal of Experimental Biology, vol. 212, no. 23, pp. 3823-3827, 2009.

[209] A. L. Koch, A. Carr, and D. W. Ehrenfeld, "The problem of opensea navigation: the migration of the green turtle to Ascension Island," Journal of Theoretical Biology, vol. 22, no. 1, pp. 163-179, 1969.

[210] M. J. Freake, R. Muheim, and J. B. Phillips, "Magnetic maps in animals: a theory comes of age?" Quarterly Review of Biology, vol. 81, no. 4, pp. 327-347, 2006.

[211] F. Papi, "General aspects," in Animal Homing, F. Papi, Ed., pp. 1-18, Chapman \& Hall, London, UK, 1992.

[212] K. W. Kenyon and D. W. Rice, "Homing of Laysan albatrosses," in The Condor, vol. 60, pp. 3-6, 1958.

[213] G. V. T. Matthews, Bird Navigation, University Press, Cambridge, UK, 1968.

[214] P. Luschi, G. R. Hughes, R. Mencacci et al., "Satellite tracking of migrating loggerhead sea turtles (Caretta caretta) displaced in the open sea," Marine Biology, vol. 143, no. 4, pp. 793-801, 2003.

[215] L. Dall'Antonia, P. Dall'Antonia, S. Benvenuti, P. Ioale, B. Massa, and F. Bonadonna, "The homing behaviour of Cory's shearwaters (Calonectris diomedea) studied by means of a direction recorder," Journal of Experimental Biology, vol. 198, no. 2, pp. 359-362, 1995.

[216] R. M. Randall, B. M. Randall, and D. Baird, "Speed of movement of jackass penguins over long distances and their possible use of ocean currents," South African Journal of Science, vol. 77, pp. 420-421, 1981.

[217] G. W. Oliver, P. A. Morris, P. H. Thorson, and B. J. Le Boeuf, "Homing behavior of juvenile northern elephant seals," Marine Mammal Science, vol. 14, no. 2, pp. 245-256, 1998.

[218] H. G. Wallraff, Avian Navigation: Pigeon Homing as a Paradigm, Springer, Berlin, Germany, 2005.

[219] G. A. Nevitt and F. Bonadonna, "Seeing the world through the nose of a bird: new developments in the sensory ecology of procellariiform seabirds," Marine Ecology Progress Series, vol. 287, pp. 292-295, 2005.

[220] N. F. Putman, C. S. Endres, C. M. F. Lohmann, and K. J. Lohmann, "Longitude perception and bicoordinate magnetic maps in sea turtles," Current Biology, vol. 21, no. 6, pp. 463-466, 2011.

[221] M. J. Fuxjager, B. S. Eastwood, and K. J. Lohmann, "Orientation of hatchling loggerhead sea turtles to regional magnetic fields along a transoceanic migratory pathway," Journal of Experimental Biology, vol. 214, no. 15, pp. 2504-2508, 2011.

[222] M. W. Merrill and M. Salmon, "Magnetic orientation by hatchling loggerhead sea turtles (Caretta caretta) from the Gulf of Mexico," Marine Biology, vol. 158, no. 1, pp. 101-112, 2011.

[223] R. Scott, R. Marsh, and G. C. Hays, "A little movement orientated to the geomagnetic field makes a big diference in strong flows," Marine Biology, vol. 159, pp. 481-488, 2012.

[224] N. F. Putman, P. Verley, T. J. Shay, and K. J. Lohmann, "Simulating transoceanic migrations of young loggerhead sea turtles: merging magnetic navigation behavior with an ocean circulation model," The Journal of Experimental Biology, vol. 215, pp. 1863-1870, 2012. 
[225] J. L. Gould, "Animal navigation: longitude at last," Current Biology, vol. 21, no. 6, pp. R225-R227, 2011.

[226] K. Cheng, "How to navigate without maps: the power of taxonlike navigation in ants," Comparative Cognition \& Behavior Reviews, vol. 7, pp. 1-22, 2012.

[227] K. J. Lohmann, C. M. F. Lohmann, L. M. Ehrhart, D. A. Bagley, and T. Swing, "Geomagnetic map used in sea-turtle navigation," Nature, vol. 428, no. 6986, pp. 909-910, 2004.

[228] F. Papi, P. Luschi, S. Åkesson, S. Capogrossi, and G. C. Hays, "Open-sea migration of magnetically disturbed sea turtles," Journal of Experimental Biology, vol. 203, no. 22, pp. 3435-3443, 2000.

[229] H. Mouritsen, K. P. Huyvaert, B. J. Frost, and D. J. Anderson, "Waved albatrosses can navigate with strong magnets attached to their head," Journal of Experimental Biology, vol. 206, no. 22, pp. 4155-4166, 2003.

[230] F. Bonadonna, C. Bajzak, S. Benhamou et al., "Orientation in the wandering albatross: interfering with magnetic perception does not affect orientation performance," Proceedings of the Royal Society B, vol. 272, no. 1562, pp. 489-495, 2005. 

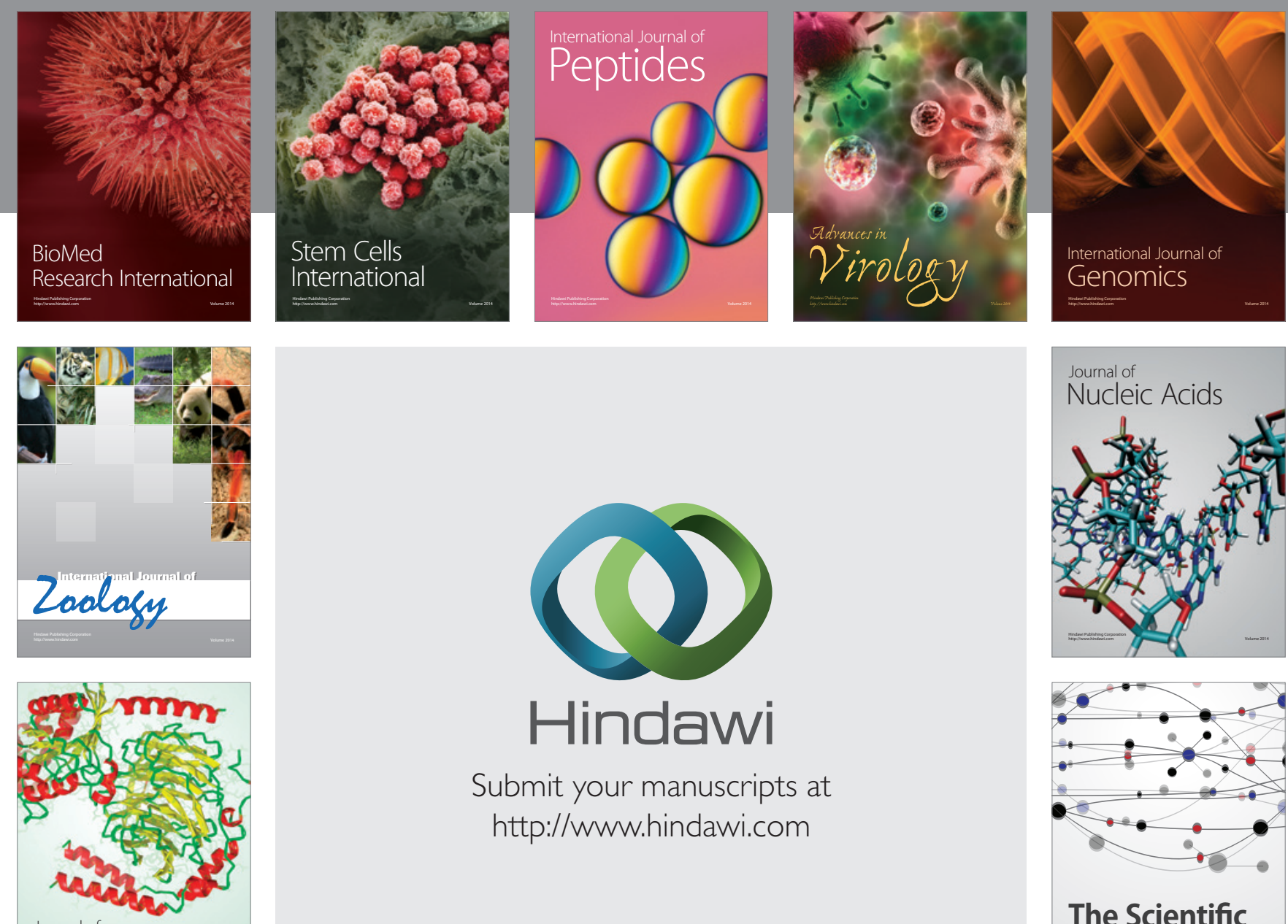

Submit your manuscripts at

http://www.hindawi.com

Journal of
Signal Transduction
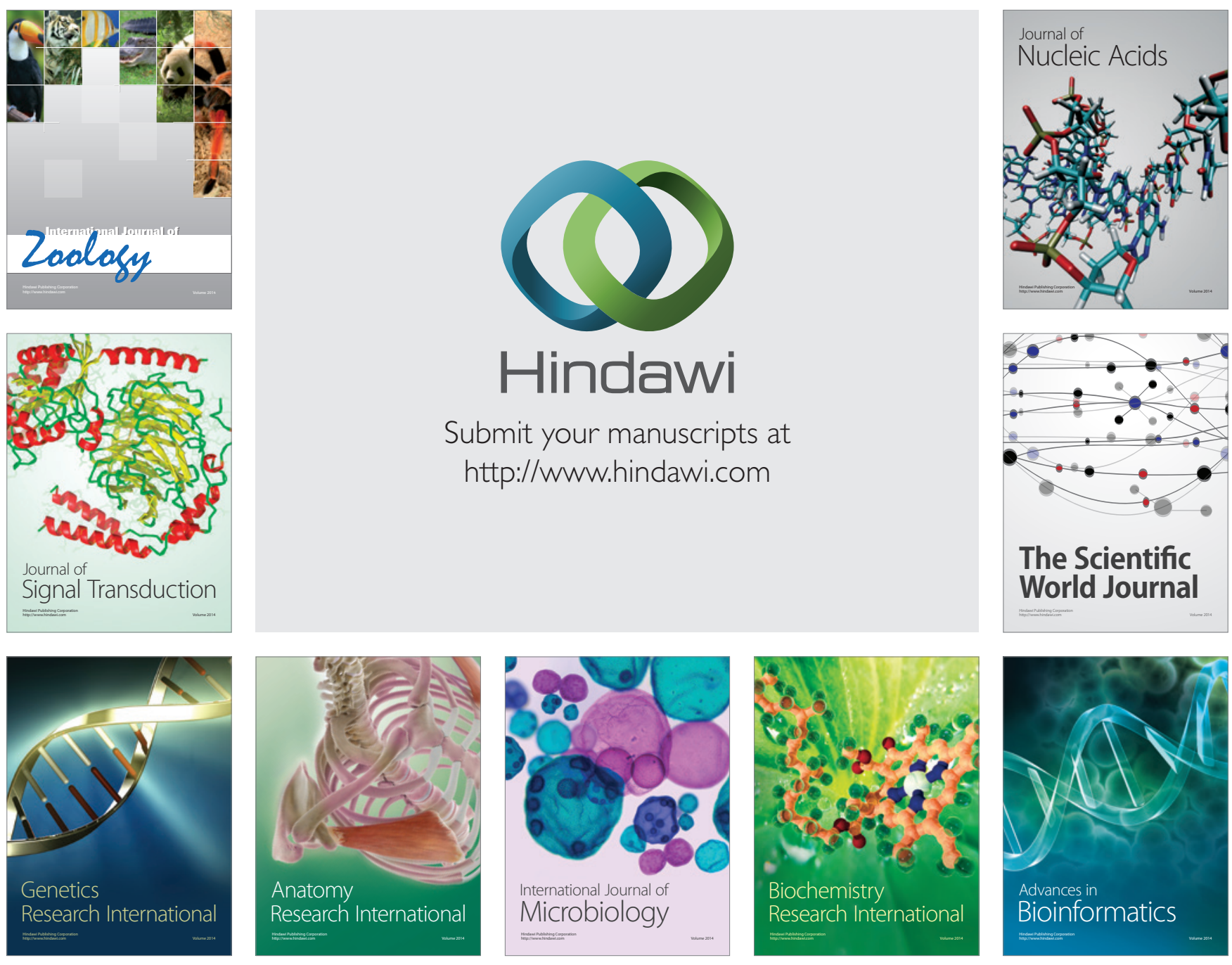

The Scientific World Journal
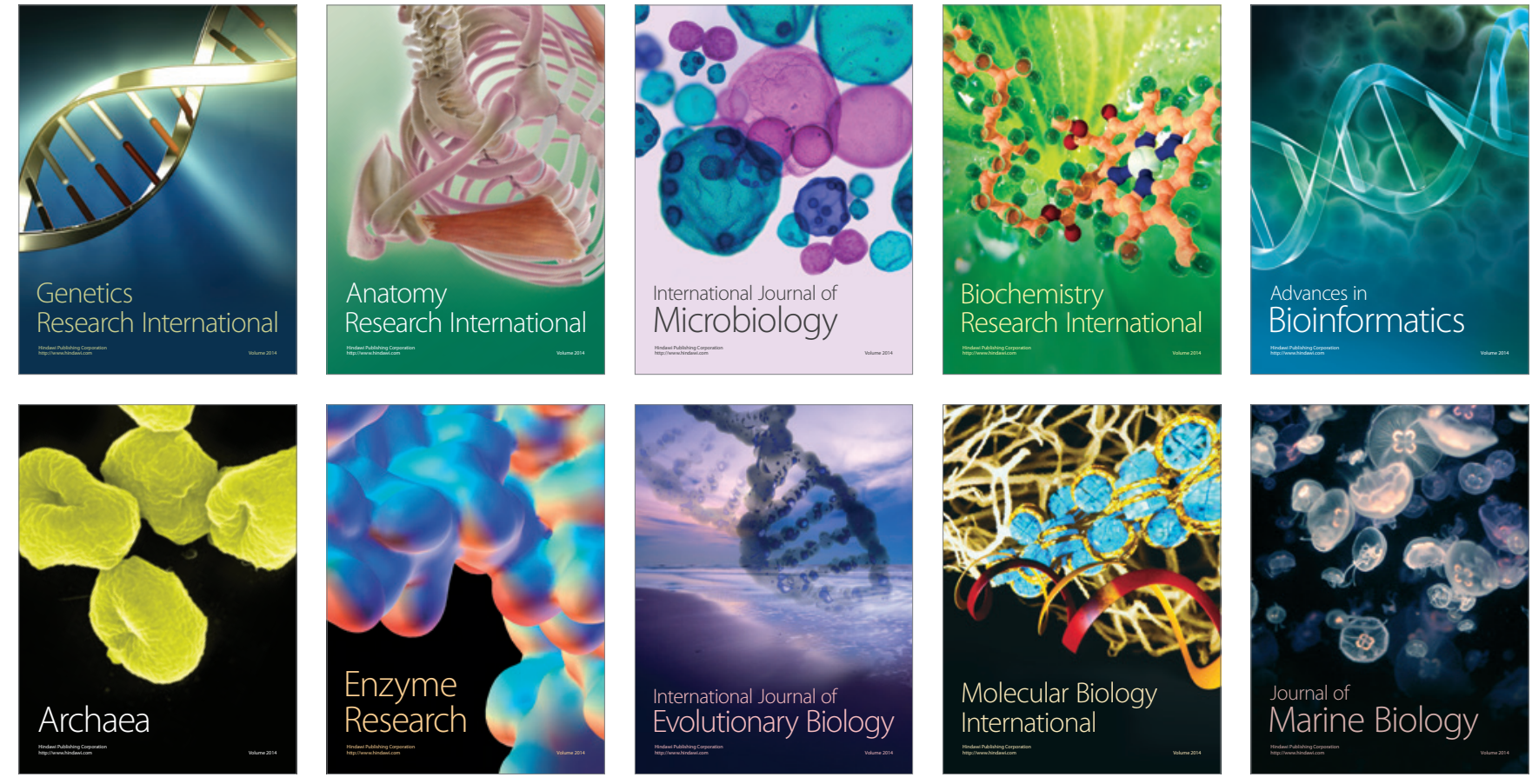